\title{
3 Research Square

\section{Genotypic response to water deficit applied at reproductive stage in rice: is the response unique across two contrasted climates?}

Isabela Pereira de Lima ( $\square$ isabelailima@yahoo.com.br)

Universidade Federal de Lavras Departamento de Agricultura https://orcid.org/0000-0002-6090-682X

Tanguy Lafarge

CIRAD

Adriano Pereira Castro

Embrapa Arroz e Feijão

Sandrine Roques

CIRAD

Armelle Soutiras

CIRAD

Anne Clement-Vidal

CIRAD

Flávia Barbosa Silva Botelho

Universidade Federal de Lavras Departamento de Agricultura

Marcel de Raissac

CIRAD

Original article

Keywords: Oryza sativa, fine phenotyping, reproductive phase, drought tolerance, yield components, flag leaf width

Posted Date: April 2nd, 2020

DOI: https://doi.org/10.21203/rs.3.rs-20289/v1

License: (9) This work is licensed under a Creative Commons Attribution 4.0 International License.

Read Full License 
1 Genotypic response to water deficit applied at reproductive stage in rice: is the 2 response unique across two contrasted climates?

3 Isabela Pereira de Lima ${ }^{1}$, Tanguy Lafarge ${ }^{2}$, Adriano Pereira de Castro ${ }^{3}$, Sandrine Roques ${ }^{2}$, 4 Armelle Soutiras ${ }^{2}$, Anne Clément-Vidal $^{2}$, Flávia Barbosa Silva Botelho ${ }^{1}$, Marcel de Raïssac ${ }^{2}$ 5

$6{ }^{1}$ Universidade Federal de Lavras, Departamento de Agricultura. Campus Universitário, 7 Lavras, MG, 37200-900, Brazil

$8 \quad{ }^{2}$ CIRAD, UMR AGAP, F-34398 Montpellier, France

9 AGAP, CIRAD, INRA, Montpellier SupAgro, University Montpellier, France

$10{ }^{3}$ Embrapa Arroz e Feijão, Rodovia GO-462, km 12, Santo Antônio de Goiás, GO, 7537511000, Brazil

12 Corresponding author: Isabela Pereira de Lima, Universidade Federal de Lavras, Departamento de Agricultura. Campus Universitário, MG, 37200-900, Brazil. isabelailima@yahoo.com.br

\section{Abstract}

Background: Rice crop is known as very sensitive to water deficit, especially during the reproductive phase when growth of vegetative organs and formation of spikelets are concomitant. The present study questioned whether the maintenance of vegetative organ expansion during a water deficit at the reproductive phase affects the reproductive structure organogenesis, and if relevant traits for adaptation can be identified. To answer these queries, the response to a same reproductive water deficit of six contrasted japonica genotypes has been analyzed under two contrasted climates differing in incident radiation, air hygrometry and temperature (greenhouse in Brazil, Sitis, and growth chamber in France, GC). 
25 Results: Under irrigation, plant growth rate was reduced in GC while crop duration was extended: the trade-offs resulted in similar plant height and biomass. From a method able to determine a posteriori the date of panicle initiation (PI), elementary processes were positioned in time, allowing to evaluate how much each process was affected, despite the diversity in phenology across genotypes. Elongation rate decreased with water deficit and was highly associated with an increase in soluble sugars in stem and flag leaf in both experiments, while starch was reduced in Sitis and negligible in GC. This unique response, however, induced a different effect across experiments on branch and spikelet formation. In short, in both experiments, maintenance of spikelet number was highly associated with maintenance of flag leaf and internode width. All variables, including branch and spikelet number, were highly affected with IAC 25 in both experiments, while variations were nonsignificant with Cirad 409. In addition, some other genotypes expressed a differential response between Sitis and GC, conveying a specific sensitivity to low radiation or to high air temperature.

Conclusions: This study highlighted the importance of finely mapping in time elementary growth processes, thanks to PI date determination, in order to detect key traits of adaptation to abiotic stress through phenotyping across genotypes of diverse phenology. The maintenance of flag leaf width or internode diameter under a mild water deficit was highlighted here as a trait associated with the maintenance of yield components.

Keywords: Oryza sativa, fine phenotyping, reproductive phase, drought tolerance, yield components, flag leaf width.

\section{Background}


Rice (Oryza sativa L.) is known to be particularly sensitive to soil water deficit because of its semi-aquatic origin (Kumar et al. 2014). Drought is therefore considered as the most important constraint reducing yield in rainfed areas (Kumar et al. 2008; Serraj et al. 2009). Water deficit may impact rice yield components according to its timing, duration and intensity: at vegetative stage, it can affect development rate, plant height, leaf area and tillering. During the reproductive phase, it mainly affects panicle branching, spikelet formation and pollen viability. After flowering, it can affect grain setting and filling and their resulting grain number and weight. Literature converges in pinpointing the reproductive phase as the most sensitive. According to Matsushima (1966), the period of time between minus eleven and minus three days before heading is the most sensitive period by its impact on final yield. Similarly, comparing the effect of water deficit at different growth periods, Lilley and Fukai (1994) and Boonjung and Fukai (1996a) demonstrated that drought has non-significant or small impact on subsequent development and grain yield when it occurs at the vegetative stage, while the same deficit during the reproductive phase causes yield and spikelet number reduction by $20-70 \%$ and $60 \%$, respectively. This can be accounted for by the phenotypic plasticity of cereals at early stages due to the trade-offs between yield components, i.e. panicle density, grain number per panicle and grain weight (Wey et al. 1998; Siband et al. 1999), particularly in rice where tillering is more effective than in maize or wheat.

Upland rice in Brazil is cultivated in large areas in the central Cerrado, where it is regularly subjected to drought but at distinct growth periods and with different intensities. Heinemann et al. (2015) classified upland ecosystems in three target populations of environment (TPE): one highly favorable environment (HFE) mainly stress-free, one favorable environment (FE) where mild water deficit occurs equally at the reproductive and terminal phases, and one least favorable environment (LFE) dominated by water deficit 
occurring at the reproductive phase. They have concluded on the priority to improve tolerance of upland rice to water deficit at the reproductive phase.

The high complexity of combining adaptive with productive traits in the same genetic materials lowed the progress for improving genetic tolerance to drought (Kumar et al. 2008). Breeding programs for tolerance opened two complementary ways: 1) the direct selection on grain yield under drought, assuming that yield is the target objective beyond the sequential mechanisms that generated it, focusing on the detection of QTL for yield and yield components (Lanceras et al. 2004;Kumar et al. 2008; Serraj et al. 2011; Kumar et al. 2014, Kumar et al. 2018; Sandhu et al. 2019;); 2) the selection based on secondary traits, that are defined as stable traits correlated to high yielding genetic materials in favorable conditions and in predominant stress situations (Lafitte et al. 2003), relying on indicators of tolerance (Subashri et al. 2009; Sellamuthu et al. 2011; He and Serraj 2012).

The present paper targets to identify, through fine phenotyping, the processes triggered underwater deficit imposed during the reproductive phase and to assess which elementary processes could be identified as adaptive, contributing to the maintenance of yield and yield components under stress.

The reproductive phase starts with panicle initiation (PI) on the main tiller, a period when plant faces the concomitance of vegetative organ growth and reproductive structure formation (Counce et al. 2000, Figure 1). At plant level, tillering goes on after PI and young tillers act as a sink for carbon, before becoming autotrophic (Matsuo and Hoshikawa, 1993). At tiller level, demand in assimilate originates from the last four inner developing leaves and the subsequent elongation of upper internodes and peduncle. Complete expansion of these organs is critical as: 1) the three last leaves are responsible for up to $86 \%$ of carbon assimilate importation of the panicle in good conditions (Cock and Yoshida, 1972) and 2) the stem and peduncle elongation drives the achievement of panicle 
exertion and flowering ability. Any reduction in leaf expansion will thus reduce assimilate supply for stem elongation and panicle formation. Oppositely, if the source is performant, assimilate surplus can also be stored in stems and sheaths, in order to support efficiently grain filling after flowering, especially under drought conditions (de Raïssac, 1992). The period between PI and flowering is thus a time of high competition for carbohydrates within a tiller, between growth of existing vegetative organs and initiation/expansion of new reproductive structures, driving (i) the dimensioning of the future carbon source (elongating leaves); (ii) the panicle exertion ability (elongating internodes and peduncle); and (iii) the dimensioning of the ultimate carbon sink (branches and spikelets under development).

\section{Figure 1 - Timing of developmental processes during the reproductive phase in rice}

The occurrence of water deficit during the reproductive phase modifies this development pattern. Tillering decreases or -if maintained- generates mainly unfertile tillers (Alou et al. 2018), and plant growth rate is slowed down, which reduces grain number and potential grain size (Lilley and Fukai 1994a). In addition, flowering is systematically delayed (Boonjung and Fukai 1996b; Lilley and Fukai 1994a), up to 2 to 3 weeks depending on the intensity of the stress (Fischer and Fukai, 2003; Lafitte et al. 2003). Garrity and O'Toole (1994), and Swamy et al. (2017), found a negative correlation between the delay in flowering and yield, and proposed to use the delay as an indicator of plant sensitivity to drought (Subashri et al. 2009; Swamy et al. 2017). In some cases, the inflorescence does not emerge, partially or fully (Lafitte et al. 2003), preventing flowering. This delay and the poor panicle exertion can be associated with the lengthening in phyllochron and be the direct consequence of the decrease in peduncle elongation (Serraj et al. 2009; He and Serraj 2012), that accounts for $70-75 \%$ of spikelet sterility (O' Toole and Namuco, 1983). The reduction in branch and spikelet number, main components determining the potential yield, is another major effect of the reproductive water deficit (Lilley and Fukai 1994b; Boonjung and Fukai 1996a). 
124 When the deficit occurs just before heading, it also affects pollen viability and the associated

125

126

127 increase in spikelet sterility (Fischer and Fukai, 2003).

In conditions of limited $\mathrm{CO}_{2}$ assimilation due to water deficit during the reproductive phase, the question raises in what extent (i) carbon is limiting for plant growth and development in terms of elongation processes and (ii) carbon investment into growing vegetative structures (leaves and stems) benefits or jeopardizes development of the reproductive structures (panicles). By comparing maize, soybean and sunflower, Boyer (1970) demonstrated that leaf enlargement decreases prior to photosynthesis in response to the reduction in water potential. This leads to an accumulation of sugars in plant organs, as observed in sunflower (Dosio et al. 2011), in coffee tree (Franck et al. 2006) or in rice (Luquet et al. 2006; Luquet et al. 2008; Rebolledo et al. 2012), giving evidence that growth is sink, rather than source, limited (Muller et al. 2011; Tardieu et al. 2018). Pantin et al. (2011) and Pantin et al. (2012) even proposed a switch from a metabolic to a hydromechanical limitation of leaf growth during the course of leaf ontogeny.

The present study analyses the response to the same reproductive water deficit of a set of six genotypes grown under two contrasted environments differing by the levels of incident radiation, air vapor pressure deficit and maximum temperature. It aims at exploring whether (i) the same mechanisms trigger the response to reproductive water deficit whatever plant growing conditions, (ii) there is synergy or competition between vegetative organ elongation and reproductive organ setting and development, and (iii) there are specific adaptive mechanisms and more tolerant genotypes able to preserve productivity during a reproductive water deficit.

\section{Methods}

\section{Genetic materials}


Six genotypes were used within two experiments. They were extracted from the

149

150

151

152

153

154

155

157

158

160

161

162

163

PRAY japonica collection, retrievable on line (GRiSP- Global Rice Phenotyping Network,

2020). The selection was made in order to compare short cycle materials with a large genetic diversity and distinct geographic origins (Table 1). Data collected in previous experiments in Brazil and in controlled environments in France (Table 2) show that the genotype classification for cycle duration is only partially maintained between experiments, with an approximatively two week lengthening of duration in France.

Table 1.

Table 1 - Upland rice genotypes used in the trials Sitis and Growth Chamber.

\begin{tabular}{ccc}
\hline Genotypes & Parents & Country of origin \\
\hline CIRAD 392 & Latsidahy x FOFIFA 62 & Madagascar \\
CIRAD 409 & CT11537 x CT10035 & Colombia \\
EM IAC 165 & Douradoprecoce x IAC 1246 & Brazil \\
GUARANI & IAC 25 x 63-83 & Brazil \\
HD 1-4 & IRAT 146 x Beira Campo & France \\
IAC 25 & Douradoprecoce x IAC 1246 & Brazil \\
\hline
\end{tabular}

Table 2.

Table 2 - Duration in days from planting obtained from previous experiment.

\begin{tabular}{cccc}
\hline \multirow{2}{*}{ Genotypes } & \multicolumn{3}{c}{ Days to Flowering } \\
\cline { 2 - 4 } & $\begin{array}{c}\text { Field 2014, } \\
\text { Brazil }\end{array}$ & $\begin{array}{c}\text { Growth Chamber } \\
\text { 2016, France }\end{array}$ & $\begin{array}{c}\text { Greenhouse } \\
\text { 2008, France }\end{array}$ \\
\hline CIRAD 392 & 58 & 75 & 71 \\
CIRAD 409 & 56 & 69 & 70 \\
EM IAC 165 & 61 & 79 & 71 \\
GUARANI & 58 & 71 & 77 \\
HD 1-4 & 59 & 68 & 77 \\
IAC 25 & 59 & 73 & 71 \\
\hline
\end{tabular}

\section{Sitis experiment (Sitis)}

This experiment was conducted in Goiânia, Brazil, at Embrapa Rice and Beans, at an altitude of $823 \mathrm{~m}$, latitude $16^{\circ} 28^{\prime} 00^{\prime \prime} \mathrm{S}$ and longitude $49^{\circ} 17^{\prime} 00^{\prime \prime} \mathrm{W}$. The SITIS (Integrated System for Induced Treatment of Drought) phenotyping platform was used. The platform, set up in the greenhouse, is composed of a set of $100 \mathrm{~cm}$ high and $25 \mathrm{~cm}$ diameter PVC pipes, each one filled with soil and placed upon an automatic scale that allows a continuous 
weighting of the pipes and monitoring of irrigation. The soil was ared latosol with medium texture, previously homogenized with a $1.25 \mathrm{~cm}$ mesh sieve to remove larger aggregates. The six genotypes were placed in a complete randomized block design with three replications and two water treatments: fully irrigated (IRR) and water stressed (STR) treatments, totalizing 36 plots. To secure three plants in each pot, a germination test has been carried out and plants were sown in excess on September 24, 2015. An application of $4 \mathrm{~g}$ of fertilizer NPK 04-14-08 was performed at planting, according to the recommendations for rice cultivation in relation with soil mineral analysis. Ten days after plant emergence, thinning was done to obtain three plants per pot. Climate conditions were monitored by an AKSO ${ }^{\circledR}$ device placed in the center of the greenhouse, continuously measuring air temperature and humidity, as well as solar radiation (Table 3).

Table 3.

Table 3 - Climate conditions in Sitis experiment.

\begin{tabular}{lccl}
\hline & Min & Average & Max \\
\hline $\mathbf{T} \min \left({ }^{\circ} \mathbf{C}\right)$ & 17.4 & 20.3 & 24.8 \\
$\mathbf{T} \max \left({ }^{\circ} \mathbf{C}\right)$ & 24.6 & 31.8 & 37.6 \\
$\operatorname{Rad}\left(\mathbf{M J} / \mathbf{m}^{2} /\right.$ day) & 1.9 & 16.7 & 26.0 \\
VDP $(\mathbf{k A})$ & 0.67 & 3.35 & 5.87 \\
\hline
\end{tabular}

T min: minimal temperature; T max: maximal temperature; Rad: daily cumulated incident radiation; VPD: Air Vapor Pressure Deficit; Min and Max are respectively the minimal and maximal values monitored during the experiment; Average is the mean value during the same period.

Soil physical analysis provided values of $24.5 \%$ and $11.5 \%$ for field capacity (FC) and wilting point (WP) respectively. Before planting, pots were slightly over-irrigated. The water in excess drained off and the weight at field capacity was determined 24 hours after this irrigation. Taking into account PVC pipe and plate weights, soil weights at FC and WP were then calculated. To quantify water availability within the pots, the FTSW indicator, Fraction of Transpirable Soil Water, was used (Sinclair and Ludlow 1986). It was calculated as the ratio between the actual available water and the maximum available water, according to the following formula: 
191

$$
F T S W=\frac{(\text { Actual soil weight }- \text { Soil weight at WP })}{(\text { Soil weight at FC }- \text { Soil weight at WP })}
$$

The pots of both treatments were adjusted daily to field capacity during the whole vegetative phase and the beginning of the reproductive phase. Two days before water stress application in the STR treatment, all pots were adjusted to FTSW $=0.8$. The water stress was applied in an "a priori" mode: using field data from Brazilian 2014 experiment (Table 2), we applied water stress 20 days before the estimated flowering date, expecting a duration of 10-14 days from PI. Stress application started on October 30, 2015 for Cirad 392, Cirad 409 and Guarani, and on November 03, 2015 for EM IAC 165, HD 1-4 and IAC 25, according to available data. After a 4-5 day period of dry-down, pots were daily adjusted to FTSW 0.4 with a bottom-up irrigation: water was simply provided in the plate below the pot, considering that observation confirmed that few primary roots had appeared at the base of the pot for each genotype, meaning that the whole soil profile was colonized. Water deficit treatment ended when at least $50 \%$ of main-tiller panicles of the irrigated treatment has emerged (when at least 5 plants on the 9 plants in the 3 irrigated replications were at heading stage).

In each pot, one plant tagged with a wool yarn and noted "plant 1" was observed for non-destructive phenological traits up to the end of the differential water treatments. This plant was then dissected while the two other plants of the pot were further grown at full irrigation from heading to grain maturity and harvesting (results not presented here).

\section{Growth Chamber experiments (GC)}

Two experiments were carried out under the same climate conditions in a growth chamber in Montpellier in 2016 and 2017: it was set up as a 12/12 hours photoperiod, with day and night temperature and air humidity regulated at $28^{\circ} \mathrm{C}$ and $20^{\circ} \mathrm{C}$, and at $65 \%$ and $90 \%$, respectively (Table 4). 
Table 4.

Table 4 - Climate conditions in Growth Chamber experiment.

\begin{tabular}{lccc}
\hline & Min & Average & Max \\
\hline T min $\left({ }^{\circ} \mathbf{C}\right)$ & 19.9 & 20.1 & 21.6 \\
T max $\left({ }^{\circ} \mathbf{C}\right)$ & 26.7 & 27.8 & 28.4 \\
Rad $\left(\mathbf{M J . m}{ }^{-2}\right.$.day $\left.^{-1}\right)$ & 1.3 & 5.8 & 9.0 \\
VDP (kPA) & 1.26 & 1.41 & 1.54 \\
\hline
\end{tabular}

T min: minimal temperature; T max: maximal temperature; Rad: daily cumulated incident radiation; VPD: Air Vapor Pressure Deficit; Min and Max are respectively the minimal and maximal values monitored during the experiment; Average is the mean value during the same period.

A first methodological experiment addressed the choice of soil substrate and the intensity of water deficit, as well as checking genotype cycle duration from planting to flowering. It was a complete randomized design with six genotypes and one water treatment (full irrigation). After germination, planting was achieved on 20 September, 2016. The number of days to panicle initiation was estimated by using the Haun index method (see below). Duration from planting to panicle initiation varied between genotypes, from 26.4 days with HD 1-4 to 36.3 days with EM IAC 165. The reference genotype IR 64 was added, to which two levels of water deficit were applied from 10 days after panicle initiation to panicle emergence: one adjusted each two days to FTSW 0.4, the other to FTSW 0.2, meaning that FTSW was lower than its ceiling value between two consecutive irrigations. The FTSW 0.2 treatment was finally too severe as it prevented any development of the plants during the reproductive phase. The FTSW 0.4 treatment was then selected (as a "mild" water deficit) for the final experiment.

The second and main experiment was conducted in a completely randomized design with six genotypes grown under two water treatments, irrigated (IRR) and stressed (STR), in three replications for a total of 36 pots. Each replicate was composed of a 3.5 liter polyethylene pot containing one single plant. Seeds were pre-germinated in an incubator set up at $30^{\circ} \mathrm{C}$ for three days. Three seedlings were transplanted on 5 January, 2017 and subsequently thinned to one plant per pot. The pots were filled with 1470 grams of a 
commercial referent substrate (Tref Riz Cirad 2), specifically adapted to rice, mixed with seven grams of Basacote $6 \mathrm{M}+$, a slow-release fertilizer. For each pot, a soil sample was weighted and oven-dried in order to determine the initial effective soil humidity and the real soil dry weight. Pot weights at FC and at WP were then deduced in order to calculate FTSW. The water deficit treatment was applied as in the Sitis experiment on an "a priori" mode: water irrigation was with hold ten days after the date of panicle initiation estimated from the pre-experiment. At the beginning of the water deficit application, the pots were covered with polystyrene micro balls to avoid water loss by soil evaporation, and to measure the plant water consumption between two consecutive irrigations. The exact quantity of water was then supplied every two days by top irrigation in order to adjust to FTSW 0.8 and 0.4 in IRR and STR treatments, respectively. The genotype-based water deficit treatment was maintained up to panicle emergence on the main tiller of the irrigated plants. Plants were then dissected and dried to obtain the partitioning of plant biomass.

\section{Measurements in both experiments}

\section{Phenological development monitoring}

Mean air temperature was calculated on a daily step in both experiments. Thermal time was calculated using Samara model values (Kumar et al. 2017), with following cardinal temperatures: $\mathrm{Tb}=10$, Topt $1=28$, Topt $2=36, \mathrm{Tmax}=44$.

The Haun Index (HI, Haun, 1973), which is calculated as the number of leaves on the main stem whose ligules is visible plus the ratio to full elongation of the portion of the visible blade length of the youngest leaf, was monitored three times a week on the main tiller of each plant. The phyllochron was calculated as the time -in days or thermal timeseparating the ligules emergence of two successive leaves of the main tiller. The early phyllochron was determined before PI and under non-limiting water supply for all genotypes, so between 14 and 27 days after planting (DAP) in Sitis, and between 11 and 24 
264 DAP in GC. Phyllochron was also determined between the onset of water treatments and

265 ligules emergence of the flag leaf (Phyllochron PI to Max HI).

266

The date of PI was retrospectively estimated for each plant, according to the

267

268

269

270

271

272 method illustrated in Figure 2 for Cirad 409 grown in GC under irrigated conditions: because the final leaf number (FLNb) on the main tiller is obtained at panicle emergence and because PI is known to occur at FLNb-4 (Nemotoet al. 1995), the precise date of PI is estimated by interpolation between the two consecutive phenological observations comprising the target PI. In the illustrated case (Figure1), FLNb is 10, PI is consequently estimated at $6 \mathrm{HI}$ and PI date estimated by interpolation at 34 DAP. This method was applied to all individual plants in both experiments. Plant height, defined as the distance between the soil and the last ligules on the main stem, was measured twice a week. Panicle emergence stage was determined when more than $50 \%$ of main tiller panicles of one genotype has emerged within the irrigated treatment.

Figure 2 - Determination of the panicle initiation date with Cirad 409 under irrigated condition in the growth chamber experiment

At panicle emergence in both experiments, after tiller counting, plant dissection has been done, to determine the following data:

- main-tiller internode 1 and 2 length and width (diameter), considering internode 1 as the first internode below the peduncle;

- main-tiller panicle, leaf and node dry weight;

- main-tiller first and second order branches number;

- main-tiller spikelet number;

- remaining tiller dry weight;

In addition, the length and width of all leaves of the main tiller were measured as soon as they were fully emerged. Specifically in Sitis experiment, plant dry weight was 
measured at thinning at 14 DAP. Specifically in GC experiment, the panicle main axis length and the total length of branches primary and secondary were measured.

\section{Carbohydrate analysis}

Flag leaf blade (FL) and internodes 1 and 2 (IN1 and IN2) were sampled early morning, or the beginning of the light period and plunged into liquid nitrogen right after sampling, freeze-dried (72h), grinded with a ball mill Retsch MM400 (particules $<50 \mu \mathrm{m}$ ) and then stored in a freezer at $-80^{\circ} \mathrm{C}$. Sugar content was measured in Sitis according to the method described by Gibon et al. (2009) and in the growth chamber by Luquet et al. (2006). The sugar extractions and starch hydrolysis are similar with two methods, the methodological difference concerns only the sugar quantification. The first method uses spectrophotometry and the other one is based on high performance liquid chromatography. Samples were previously used to ensure that the results could be comparable. The results are expressed as glucose equivalents per unit dry matter $\left(\mathrm{mg}_{\mathrm{g}} \mathrm{g}^{-1}\right)$ for starch (Starch) and as soluble sugar (SolSug) per unit dry matter ( $\left.\mathrm{mg}^{-\mathrm{g}^{-1}}\right)$ corresponding to the amount in hexoses and sucrose.

\section{Gas exchange measurement}

In Sitis, transpiration was measured at the end of the experiment, between 9 and 11 a.m., with the flag leaf of each plant $\mathrm{n}^{\circ} 1$, using the LC-Pro-IRGA® device, regulated at a $300 \mathrm{ml} \cdot \mathrm{min}^{-1}$ air flow with a $1200 \mu \mathrm{mol} \cdot \mathrm{m}^{-2} \cdot \mathrm{s}^{-1}$ light source.

In the growth chamber, photosynthesis and transpiration were measured the day before dissection by the Walz GFS 3000 .

\section{Derived variable calculation}

The main tiller elongation rate was calculated as the increase in height during the stress period (in IRR and STR plants) divided by the number of days. An estimation of the relative plant growth rate (RGR) was calculated differently in Sitis and GC experiments. 
In Sitis, genotype shoot dry weight was measured on six plants from the IRR treatment at 14 DAP-at time of thinning- and at panicle emergence. RGR was then calculated for IRR treatment as following:

$$
R G R=\frac{\Delta \operatorname{Ln}(\text { shoot dry weight })}{\Delta \text { Date }}
$$

The mean genotype RGR was then used to estimate by intrapolation shoot dry weight of plants at the onset of water deficit application. Considering shoot dry weight at the onset of water deficit and at heading (end of the experiment), RGR (g.day ${ }^{-1}$ ) and GR (Growth rate - g.day ${ }^{-1}$ ) were calculated during the whole period when differential water treatments were effective. In the growth chamber, an allometric correlation between height and biomass was used to estimate the shoot dry weight of the plants at the onset of water deficit application.

In GC, because pots were covered by polystyrene bills preventing direct soil evaporation, the monitoring of pot weights before and after irrigation allows calculating the daily plant transpiration, as well as a cumulated plant transpiration during the differential water treatment period. The cumulated water use efficiency was then calculated as the ratio of the increase in biomass to the amount of water consumed during the same period.

To quantify genotype response to water deficit, response indexes were calculated as the relative variation between IRR and STR treatments, as defined below:

$$
\text { Responde index }=\frac{(S T R-I R R)}{I R R}
$$

Where:

STR is the genotype adjusted mean of the considered variable for the water deficit treatment; IRR is the adjusted mean of the considered variable for the irrigated treatment.

\section{Statistical analysis}


Anovas were run using R packages “agricolae” (de Mendiburu 2014),

338 "ScottKnot" (Jelihovschi et al. 2014), "doBy" (Hojsgaard et al. 2019) and "ggplot2"

339 (Wickham 2016). The response indexes were validated by a test of orthogonal contrasts,

340 where the adjusted means of the IRR treatment were compared to the adjusted means of the

341 STR treatment, using F Test and R software.

342 Results

343 Impact of the timing of water deficit on developmental processes.

Identification of the precise dates of occurrence of water deficit for each genotype was determined before going through any analysis. First, the date of panicle initiation (PI) was retrospectively estimated for each individual plant, as described in Methods. The time lag between PI and the actual start of water deficit application was then determined: a global index of the relative progress of the reproductive phase at time of stress application was calculated, as the ratio (in days) of the elapsed time from PI to the onset of water deficit to the total reproductive phase duration (Table 5).

351 Table 5.

Table 5 - Mean progress of reproductive phase at start of water deficit application.

\begin{tabular}{cccccc}
\hline Genotypes & Trial & $\begin{array}{c}\text { Heading } \\
\text { (DAP) }\end{array}$ & $\begin{array}{c}\text { Water deficit } \\
\text { application } \\
\text { (Days after } \\
\text { PI) }\end{array}$ & $\begin{array}{c}\text { Reproductive } \\
\text { phase } \\
\text { duration } \\
\text { (Days) }\end{array}$ & $\begin{array}{c}\text { Reproductive } \\
\text { phase achieved } \\
\text { (\%) }\end{array}$ \\
\hline CIRAD 392 & & 53 & 15.0 & 32.0 & 46.8 \\
CIRAD 409 & & 47 & 15.3 & 26.3 & 58.1 \\
EM IAC 165 & SITIS & 54 & 16.0 & 30.0 & 53.3 \\
GUARANI & & 53 & 13.0 & 30.0 & 43.3 \\
HD 1-4 & & 54 & 17.7 & 31.7 & 55.8 \\
IAC 25 & & 54 & 16.0 & 30.0 & 53.3 \\
\hline Mean & & $\mathbf{5 2 . 5}$ & $\mathbf{1 5 . 6}$ & $\mathbf{3 0 . 1}$ & $\mathbf{5 1 . 8}$ \\
\hline CIRAD 392 & & 68 & 7.0 & 41.0 & 17,0 \\
CIRAD 409 & Growth & 59 & 2.0 & 31.0 & 6,4 \\
EM IAC 165 & Chamber & 71 & 9.0 & 45.0 & 20,0 \\
GUARANI & $\mathbf{G}$ (GC) & 64 & 3.0 & 34.0 & 8,8 \\
HDD 1-4 & & 62 & 5.0 & 36.0 & 13,9 \\
IAC 25 & & 64 & 10.0 & 39.0 & 25,6 \\
\hline \multicolumn{1}{c}{ Mean } & & $\mathbf{6 4 . 6}$ & $\mathbf{6 . 0}$ & $\mathbf{3 7 . 7}$ & $\mathbf{1 5 . 3}$ \\
\hline
\end{tabular}



relative progress of the reproductive phase was $15.3 \%$ in GC, and $51.8 \%$ in Sitis. This was mainly due to a lack of reliable field data in Sitis to predict plant cycle duration and so to estimate time of PI, while the pre-experiment in GC with controlled conditions helped to overcome this difficulty. Thus, the water deficit was applied later in Sitis than in GC, but with the same intensity as determined by pot water content adjusted at FTSW 0.4 each two days on both experiments.

The rate in time to which each single phenological process was affected due to the application of water deficit was finally computed for each genotype and in each trial (Tables 6 and 7), with reference to the timing and position of each one of these processes (Figure 1). To develop a subsequent reliable analysis, these rates were used as the basis to only study the processes that were completed during water deficit.

Table 6.

Table 6 - Impact of water deficit on reproductive phase processes in Sitis.

Table 7.

Table 7 - Impact of water deficit on reproductive phase processes in Growth chamber. One key element of this study was to quantify the effect of water deficit on any phenological processes that occurred at the early reproductive phase (flag leaf formation, bract formation) since these processes were over before the end of the water treatment which occurred at panicle exertion in the irrigated plants. So, in the water stress treatment, these processes were fully affected by water deficit in one or both experiments. This was, however, irrelevant to quantify the effect of water deficit on processes that were still on-going heading, like internode 1 and peduncle elongation, or pollen viability. Indeed, at the time of high elongation rate of internode 1 or peduncle, any slight delay in development due to the application of water deficit can lead to huge differences in internode and peduncle lengths, 
as measured with destructive observation. Any differences between treatments were thus the consequence of the effect of water deficit but also of the likely delay in plant development. In this way, the inter-genotype and inter-treatment variability in peduncle length data were huge - and in a lower extent that in internode 1-, but that has included a strong effect of the delay in phenology. These variables, as well as pollen viability, have not been considered for further analysis

The robustness of the estimates at Tables 6 and 7 was confirmed by the comparison of the flag leaf length. The water deficit was not applied during the leaf elongation phase in Sitis while it was in GC, hence, no effect was expected in Sitis to the difference of GC. An anova conducted separately on both experiments confirmed this hypothesis, with a significant effect in GC only (Table 8 and Figure 3). As no Treatments $X$ Genotypes interaction was observed in GC, it is reported that leaf elongation across genotypes reacted the same way to water availability.

\section{Table 8.}

Table 8- Leaf length analysis of variance in Sitis and Growth Chamber.

\begin{tabular}{ccccccc}
\hline \multirow{2}{*}{ SV } & \multicolumn{3}{c}{ Sitis } & \multicolumn{3}{c}{ Growth Chamber } \\
\cline { 2 - 7 } & DF & $\operatorname{Pr}(>\mathbf{F})$ & Significance & DF & $\operatorname{Pr}(>\mathbf{F})$ & Significance \\
\hline Block & 2 & 0.86 & NS & - & - & - \\
Treatments & 1 & 0.40 & NS & 1 & $\mathbf{0 . 0 0}$ & $* * *$ \\
Genotypes & 5 & 0.27 & NS & 5 & 0.30 & NS \\
Trmnt. X Genotypes & 5 & 0.22 & NS & 5 & 0.96 & NS \\
\hline
\end{tabular}

\begin{tabular}{ccc}
\hline $\mathbf{C V} \%$ & 11.79 & 19.36 \\
\hline
\end{tabular}
Means were calculated on 6 genotypes x 3 replicates (18 values) for each water treatment in each experiment. The response index was calculated as described in Material \& Methods. NS: Non significant; ***: significant at $\mathrm{P}<0.001$

\section{Figure 3 - Flag leaf length in relation with the experiments and water treatments.}

Lower internode elongation was not submitted to water deficit in Sitis, while it was partially in GC. As reported earlier, some other processes were fully affected since their initiation (so reported as $100 \%$ in Tables 6 and 7) but were likely interrupted before their completion (Internode 1 and peduncle elongation, pollen viability) due to the end of the 
402

403

404

405

406

407

408

409

410

411

412

413

414

415

416

417

418

419

420

421

422

423

424

425

experiment. These processes were excluded from the analysis. In contrast, some processes were affected by water deficit, partially in Sitis and totally in GC (see Tables 6 and 7), like branching I and II (32 and 100\% respectively), internode 2 elongation (36 and 100\% respectively) and spikelet formation (88 and 100\% respectively). These were completed at the end of experiment and are the main processes that will be investigated in the subsequent analyses of this paper.

\section{Effect of environmental conditions on plant development rate and cycle duration}

The cumulated thermal time from planting to heading increased quicker in Sitis than in GC (Figure 4). The slope, indicating the mean daily cumulated thermal time, was $17.5^{\circ} \mathrm{C}$ days and $13.7^{\circ} \mathrm{C}$ days respectively. The slower accumulation of thermal time from planting to heading in GC accounted for its longer growth period duration (in days), the flowering date occurring 16.7 days later and the reproductive phase lasting 6.5 days longer (37.7 vs. 30.1 days, Table 5) in GC than Sitis. Based on thermal time, the early phyllochron was also longer in GC than Sitis for the six genotypes. The ratio of phyllochron of GC to Sitis ranged from 1.36 in Cirad 409 to 1.17 in IAC 25. Another cause of the rise in cycle duration in GC was the increase in the final leaf number on the main tiller (Table 9), between 1 to 1.5 leaf respective of the genotype. Conclusively, the longer cycle duration (in days) in $\mathrm{GC}$ is due to the combined effect of a lower thermal time accumulation, a lengthening in phyllochron measured in ${ }^{\circ}$ days and a higher number of emitted leaves.

Figure 4 - Cumulated thermal time in Sitis and Growth Chamber experiments in function of calendar time

Table 9.

Table 9 - Final leaf number on the main stem in Sitis and Growth Chamber experiments.

\begin{tabular}{ccc}
\hline Genotypes & SITIS & Growth Chamber \\
\hline CIRAD 392 & 9.0 & 11.3 \\
CIRAD 409 & 8.7 & 10.3 \\
\hline
\end{tabular}




\begin{tabular}{ccc}
\hline EM IAC 165 & 9.0 & 10.2 \\
GUARANI & 9.2 & 11.2 \\
HD 1-4 & 8.7 & 9.5 \\
IAC 25 & 9.0 & 10.0 \\
\hline
\end{tabular}

426

427 Effect of environmental conditions on plant morphological and physiological traits and

428 their response to water deficit

429 Relevant traits that were affected by water deficit in at least one experiment and

430 whose processes were completed at heading were studied in a split-plot analysis. This

431 analysis considered that both experiments display a completely randomized design, with the

432 first factor (the experiments) at two levels and the second factor (water treatments) at two

433 levels, the genotype factor not being considered. Data are shown at Table 10.

434 Table 10.

435 Table 10 - Effect of experiment conditions and water treatments on rice plant traits.

\begin{tabular}{|c|c|c|c|c|c|c|c|c|c|}
\hline \multirow[b]{3}{*}{ Traits } & \multicolumn{4}{|c|}{ Means } & \multicolumn{2}{|c|}{ Response Index } & \multicolumn{3}{|c|}{ Significancy } \\
\hline & \multicolumn{2}{|c|}{ Sitis } & \multicolumn{2}{|c|}{ Growth Chamber } & \multirow{2}{*}{ Sitis } & \multirow{2}{*}{$\begin{array}{l}\text { Growth } \\
\text { Chamber }\end{array}$} & \multirow{2}{*}{$\operatorname{Exp}$} & \multirow{2}{*}{ Trtmnt } & \multirow{2}{*}{$\begin{array}{c}\text { Exp x } \\
\text { Trmnt }\end{array}$} \\
\hline & Irrigated & Stressed & Irrigated & Stressed & & & & & \\
\hline TillNb & 9.7 & 8.7 & 6.8 & 6.9 & -0.11 & 0.01 & $* * *$ & NS & NS \\
\hline Plant Height (mm) & 697.9 & 561.4 & 813.4 & 689.2 & -0.20 & -0.15 & $* * *$ & $* * *$ & NS \\
\hline Plant Biomass (g) & 16.2 & 13.0 & 15.7 & 13.2 & -0.20 & -0.16 & NS & $* * *$ & NS \\
\hline GrowthRate (g.day $\left.{ }^{-1}\right)$ & 1.14 & 0.90 & 0.40 & 0.33 & -0.21 & -0.18 & $* * *$ & $* * *$ & NS \\
\hline FLLength (mm) & 436.5 & 428.1 & 604.2 & 499.3 & -0.02 & -0.17 & $* * *$ & $* * *$ & $* * *$ \\
\hline FLWidth (mm) & 17.3 & 17.3 & 18.7 & 17.3 & 0.00 & -0.07 & NS & NS & NS \\
\hline IN2Length (mm) & 141.3 & 104.1 & 140.3 & 119.3 & -0.26 & -0.15 & NS & $* * *$ & NS \\
\hline IN2Width (mm) & 5.6 & 5.3 & 5.9 & 5.1 & -0.04 & -0.13 & NS & $* * *$ & NS \\
\hline TotalBranchNb & 35.2 & 29.8 & 37.9 & 28.2 & -0.15 & -0.26 & NS & $* * *$ & NS \\
\hline SpikeletNb & 155.2 & 131.9 & 156.7 & 118.8 & -0.15 & -0.24 & NS & $* * *$ & NS \\
\hline ElongRate (mm.day $\left.{ }^{-1}\right)$ & 26.3 & 16.3 & 14.6 & 11.1 & -0.38 & -0.24 & $* * *$ & $* * *$ & $* * *$ \\
\hline FLSolSug (mg.g $\left.{ }^{-1}\right)$ & 66.0 & 108.7 & 60.7 & 72.9 & 0.65 & 0.20 & $* * *$ & $* * *$ & $* * *$ \\
\hline $\operatorname{FLStarch}\left(\mathbf{m g . g}{ }^{-1}\right)$ & 54.5 & 47.5 & 0.7 & 0.8 & -0.13 & 0.14 & $* * *$ & $* * *$ & $* * *$ \\
\hline IN2SolSug (mg.g $\left.{ }^{-1}\right)$ & 55.2 & 104.9 & 78.4 & 88.7 & 0.90 & 0.13 & NS & $*$ & NS \\
\hline IN2Starch (mg.g-1) & 128.4 & 108.1 & 25.8 & 24.5 & -0.16 & -0.05 & $*$ & NS & NS \\
\hline LeafTransp (mmol.m $\left.\mathrm{m}^{-2} \cdot \mathrm{s}^{-1}\right)$ & 4.6 & 3.9 & 4.4 & 3.8 & -0.15 & -0.14 & NS & $*$ & NS \\
\hline Phyllochron (days) & 7.9 & 9.5 & 7.8 & 8.5 & 0.21 & 0.09 & NS & NS & NS \\
\hline
\end{tabular}

436 Means were calculated on 6 genotypes x 3 replications (18 values) for each water treatment in each experiment.

437 The response index was calculated as described in Material \& Methods. NS: Non significant; *: significant at $\mathrm{P}<0.05$; **: significant at $\mathrm{P}<0.01$; and ***: significant at $\mathrm{P}<0.001$. 
Under irrigated conditions, whole plant growth rate during reproductive phase

441

442

443

444

445

446

447

448

449

450

451

452

453

454

455

456

457

458

459

460

461

462

463

464 decreased by $64 \%$ from Sitis to GC (from 1.14 to 0.40 g.day ${ }^{-1}$ ) which was associated with a $65 \%$ decrease in incoming radiation (from $16.7 \mathrm{MJ} \cdot \mathrm{m}^{-2}$.day ${ }^{-1}$ to $5.8 \mathrm{MJ} \cdot \mathrm{m}^{-2}$.day ${ }^{-1}$ ), and a $24 \%$ decrease in maximum daily temperature (from 37.6 to $28.4{ }^{\circ} \mathrm{C}$, see Tables 3 and 4 ), leading to a significant reduction in tiller number per plant (6.8 in GC vs. 9.7 in Sitis). In the same line, while concentration of soluble sugars was in the same range across both environments in the flag leaf $\left(66.0 \mathrm{mg} \cdot \mathrm{g}^{-1}\right.$ in Sitis vs $60.7 \mathrm{mg} \cdot \mathrm{g}^{-1}$ in GC) and in internode 2 (55.2 mg.g ${ }^{-1}$ in Sitis vs $78.4 \mathrm{mg} \cdot \mathrm{g}^{-1}$ in GC), that of starch was drastically reduced from Sitis to GC for these 2 organs (from $54.5 \mathrm{mg} . \mathrm{g}^{-1}$ to $0.7 \mathrm{mg} \cdot \mathrm{g}^{-1}$ in flag leaf and from $128.4 \mathrm{mg} . \mathrm{g}^{-1}$ to $25.4 \mathrm{mg} \cdot \mathrm{g}^{-1}$ in internode 2). Interestingly, as a consequence of the delay in heading time in GC, the final whole plant biomass was not significantly different between both experiments (16.2 $\mathrm{g}$ in Sitis and $15.7 \mathrm{~g}$ in $\mathrm{GC}$ ). The extended growth duration in GC contributed in generating taller plants than in Sitis $(813.4 \mathrm{~mm}$ vs. $697.9 \mathrm{~mm})$ whereas stem elongation rate was significantly lower(14.6 mm.day ${ }^{-1}$ in GC vs $26.3 \mathrm{~mm}$.day ${ }^{-1}$ in Sitis). Similarly, flag leaf was longer in GC $(604.2 \mathrm{~mm})$ than in Sitis $(436.5 \mathrm{~mm})$. These results are in accordance with the reduction of leaf elongation observed in maize in response to high VPD, as it was in S (Tardieu 2005; Bouchabké et al. 2006). Like plant biomass, some other traits relative to organ morphology and number determined during the reproductive phase were not significantly modified across growing conditions: no significant differences were observed for internode 2 length $(141.3 \mathrm{~mm}$ vs $140.3 \mathrm{~mm})$, internode 2 width (5.6 mm vs 5.9 $\mathrm{mm}$ ), total branch number (35.2 vs 37.9$)$ and spikelet number (155.2 vs 156.7). The transpiration rate of the flag leaf of the main tiller measured right before heading did not also differ between experiments.

Experiment $\mathrm{x}$ Treatment interactions were revealed for some traits (Table 10) and can be explained by two main reasons. The first one is the lag in the timing of water 
deficit applications between both experiments: respective to the physiological time, the deficit was applied later in Sitis than in GC and so did not affect some processes the same way. As already seen, flag leaf length was not affected in Sitis, but was in GC as its elongation was already over when the deficit was applied in GC. Similarly but not significantly, flag leaf width was not affected in Sitis but was in GC. The second reason is directly related to environment conditions: in the flag leaf, in response to water deficit, soluble sugars increased poorly in GC (from 60.7 to $72.9 \mathrm{mg} . \mathrm{g}^{-1}$ ) and strongly in Sitis (from 66.0 to $108.7 \mathrm{mg} . \mathrm{g}^{-1}$ ) (Table 10 ). At the same time, starch content was stable and nearly negligible in GC (from 0.7 to $0.8 \mathrm{mg} \cdot \mathrm{g}^{-1}$ ) while it decreased in Sitis (from 54.5 to $47.5 \mathrm{mg} . \mathrm{g}^{-}$ ${ }^{1}$ ), in agreement with previous results (Rebolledo et al. 2012) and in accordance with the low radiation and the consecutive poor carbon availability in GC. No other interactions in response to water deficit has been detected with the other traits under study, i.e. plant height and biomass, internode 2 length and width, branch and spikelet number and final leaf transpiration. As an example, a strong correlation was reported for the length of internode 2 between values reported from GC and those reported from Sitis (Figure 5), giving consistency to our results.

Figure 5 - Relationship between internode 2 length in Growth Chamber and Sitis experiments

\section{Genotype response to water deficit at reproductive phase}

The integrated response of the six genotypes to water deficit was analyzed based on the response indexes as defined in Methods. The PCA on the response indexes of all the studied morphological and physiological traits was run using the variations of total branch number $(\Delta$ TotBranchNb) and spikelet number $(\Delta$ SpikeletNb) as supplementary variables: these two variables were considered as the final products of the plant at the stage when the 
trial was stopped (heading) and so the best indicators of plant adaptability to water deficit established during the reproductive stage. The correlation matrix is given in Table 11.

\section{Table 11 - Correlations matrix of the studied variables.}

As expected, $\Delta$ TotBranchNb and $\Delta$ SpikeletNb were highly correlated $\left(+0.945^{* * *}\right)$ to each other. The $\Delta$ TotBranch $\mathrm{Nb}$ was highly correlated to $\Delta$ FLLength $\left(+0.730^{* *}\right), \Delta$ FLWidth $\left(+0.736^{* *}\right)$ and $\Delta \mathrm{IN} 2$ Width $\left(+0.728^{* *}\right)$ : the reduction in flag leaf and internode 2 dimensions in response to water deficit was closely associated with the reduction in the panicle branch number. The $\Delta$ SpikeletNb was correlated also to the same variables at $5 \%(*)$. The $\Delta$ LeafTransp was also positively correlated to $\Delta$ SpikeletNb $\left(+0.578^{*}\right)$ and logically more weakly to $\Delta \mathrm{TotBranchNb}\left(+0.526^{\circ}\right)$, as the formation of branches occurs prior to spikelet formation.

In addition, $\Delta \mathrm{TillNb}$ was the only trait negatively correlated to $\Delta \mathrm{TotBranchNb}$ (at $10 \%$ ), while it was positively and strongly correlated to $\Delta$ GrowthRate. And $\Delta$ GrowthRate did not display any correlation with other traits, representative neither of organ growth (morphogenesis), or of organ generation (organogenesis). The $\Delta$ ElongRate was positively correlated to $\Delta \mathrm{IN} 2$ Length $(* *)$ and $\Delta \mathrm{FLStarch}(*)$, and negatively to $\Delta$ Phyllochron $(* *)$ and $\Delta$ FLSolSug $(*)$. The $\Delta$ Phyllochron was positively correlated to $\Delta \mathrm{IN} 2$ SolSug.

The PCA representation on the two first components explained $55.4 \%$ of the total variability (Figure 6). The first component (31.2\%) was principally defined (i) positively by $\Delta$ ElongRate and $\Delta \mathrm{IN} 2$ Length and (ii) negatively by $\Delta$ FLSolSug and $\Delta$ Phyllochoron. The second component (24.4\%) was defined positively by $\Delta \mathrm{IN} 2 \mathrm{Width}$ and $\Delta$ FLWidth and negatively $\Delta$ TillNb.

Figure 6 - Principal Component Analysis representation on the two first components of the response index 
514 fully positioned positively on the second component, and tightly associated with the

515 maintenance of flag leaf and internode 2 diameters ( $\Delta$ FLWidth and $\Delta \mathrm{IN} 2 \mathrm{Width}$ ). Tiller number variation was fully opposed to yield components and was the unique trait displaying high negative correlations with them $(-0.511$ and -0.470 with $\Delta$ TotBranchNb and $\Delta$ SpikeletNb, respectively): this correlation means that the more tillers were initiated under water deficit, during the reproductive phase, the less branch and spikelet number was set in the main tiller panicle.

A strong difference between Sitis and Growth Chamber experiments and a large gradient of genotype responses are visible in Figure 6 and Table 12. In both experiments, water deficit was associated with a reduction in the stem elongation process ( $\Delta$ ElongRate, $\Delta \mathrm{IN} 2$ Length) and organ starch content ( $\Delta \mathrm{FLStarch}$ and $\Delta \mathrm{IN} 2 \mathrm{Starch})$, while phyllochron and soluble sugar content increased ( $\Delta$ FLSolSug and $\Delta \mathrm{IN} 2$ SolSug), illustrated by the genotype gradient along the PCA first component (Figure 6). In contrast, along the second component, the genotype increase in soluble sugar was rather associated with the maintenance in yield components in Sitis but not in GC. Interestingly, the singular behavior of Cirad 409, minimizing its response to water deficit in both experiments, is noticeable.

Table 12.

Table 12 - Response index in Sitis and in Growth Chamber experiments for all studied traits and genotypes.

In Sitis, no trait variation was observed with Cirad 409, except for flag leaf starch ( $\triangle$ FLStarch), which was reduced by $28 \%$, while the reduction was $39 \%$ in IAC 25 and $13 \%$ in EM IAC 165. As the most sensitive trait, soluble sugars increased up to $97 \%$ in the flag leaf (HD 1-4) and to $148 \%$ in the internode 2 (Cirad 392). Main tiller elongation rate was also very sensitive to water deficit, with significant variations ranging between $31 \%$ (HD 1- 
538 4) and 55\% (EM IAC 165). Variations of total branch number were smaller, mainly nonsignificant, except in IAC 25 and HD 1-4 (-31\% and -23\% respectively). Spikelet number was also poorly affected, except in IAC 25 (-33\%), confirming the weak adaptability of this genotype. Interestingly, values of yield components were maintained under water deficit with Cirad 392, while significant variations in stem elongation and soluble sugar contents were reported. 409: in this genotype, all variables were maintained unchanged under moderate water deficit, as observed in Sitis (with the exception of $\triangle F L S t a r c h$ ). The evolution is quite different with other genotypes. Variation in flag leaf soluble sugars was very poor compared to Sitis, only Guarani and EM IAC 165 displayed a significant increase by $+27 \%$ and $+29 \%$, respectively. Oppositely, variation in soluble sugars of internode 2 was remarkably contrasted depending on the genotype: it ranged from a reduction of $62 \%$ with Cirad 392 , with a stability with HD $1-4$, to an increase of $191 \%$ with EM IAC 165 . And the sensitivity of the elongation rate to water deficit was also remarkable within all genotypes except with Cirad 409: it decreased from 17\% (Guarani) to 34\% (Cirad 392). Finally, except for the case of HD 1-4, yield components were more affected in GC than in Sitis: EM IAC 165 and IAC 25 were the most sensitive genotypes, with reduction in branch number by 46 and $25 \%$ and spikelet number by 45 and $26 \%$, respectively.

\section{Discussion}

In this study, we have investigated the response to a water deficit applied during the reproductive phase of six rice genotypes grown under two contrasted climate conditions: high temperatures, high radiation and VPD in Sitis; optimum temperatures, low radiation and VPD in GC.

\section{Phenotyping for tolerance to mild water deficit at reproductive stage}


A varietal comparative analysis of the effect of a water deficit during the reproductive phase in cereals requires applying the constraint at the same phenological age for all varieties. Indeed, considering the precise timing of initiation and development of each organ during that phase, any time lag in the phenology of two varieties would prevent from comparing the effect of a constraint established at a single date on plant traits, like organ size or yield components (grain weight, grain and spikelet number). Indeed here, a strong correlation between time of water deficit application and its impact on organ development was highlighted: flag leaf length was not affected when water deficit application was delayed (Sitis), but was in case of an earlier application (Growth Chamber). One major challenge of

572 the present study was yet to apply the water deficit at the same phenological age whatever the genotype. This was achieved in Montpellier due to: i) a preliminary dedicated trial whose goal was to observe the respective phenology of each variety; ii) a highly controlled and identical environment for both the preliminary and the main trials. However, this was only partially achieved in Sitis as the daily variation of radiation, temperature and photoperiod has impacted plant phenology and prevented the authors from (a) considering the preliminary available field data as useful to predict plant phenology and (b) setting up an initial trial (which should have been organized a year earlier) because of the photoperiod sensitivity.

The use of thermal time, instead of days, is widely accepted as a common way to overcome this difficulty to take into account phenological stage durations. Underlying the assertion that development rate is driven by temperature (Jamieson et al. 1995), thermal time turns possible the comparison of plant phenology across environments despite their differences in temperature (Bouman et al. 2001). However, the rate of leaf emergence in the present study, even expressed in thermal time, differed across trials, the phyllochron being

587 shorter in Sitis than in GC. We hypothesized here that the temperature effect may have been 
modified by an additional effect of daily radiation, the later one displaying average values of 5.8 MJ.m ${ }^{-2}$.day ${ }^{-1}$ in GC and 16.7 MJ.m .day $^{-1}$ in Sitis. In rice, Islam and Morison (1992) introduced the photothermal quotient (PQ) - as the ratio between cumulated radiation and cumulated thermal time $\left(\mathrm{MJ} \cdot \mathrm{m}^{-2} .{ }^{\circ} \mathrm{C}^{-1}\right)$ - during the 30 days- day period before harvest in order to predict yield. Recently, Baumont et al. (2019) indicated in wheat the joint role of temperature and carbon availability on plant development rate and concluded that the use of photothermal quotient (PQ) is relevant to better model cycle durations in different light and temperature environments. In order to compare phyllochron between environments, it is suggested here that thermal time is appropriate when environments differ mainly by their temperature conditions, while PQ is when facing contrasted environments, differing by incident radiation, temperature and VPD, as it was the case in our study.

The phenological framework described here in Figure 2 allowed to determine a posteriori the PI dates for each genotype and to quantify how much in time each process of plant development has been affected by the water deficit (Figure 1, Tables 6 and 7). This was possible even without a tight control of the onset of water deficit in relation with the timing of the reproductive phase. A comparative analysis between sites of the effect of water deficit, having the same intensity and timing between genotypes within one experiment, could then be run between the two sites, as long as it has focused on traits that were actually affected by water deficit in both experiments.

This a posteriori determination of the PI date shall be particularly useful in field conditions, within breeder's trials or large-scale phenotyping trials, where the triggering of a water deficit cannot be driven at the plant or genotype level, as we did with plants in pipes or in pots. Indeed, in case of a large plant diversity within the breeder's field, the occurrence of a single water deficit period might affect plants at quite distinct stages (some might be already in the reproductive while others are still in the vegetative). In the field, to deal with 
613 a large panel of genotypes differing in earliness, and so to minimize this discrepancy in 614 phenology, several methods have been used in the literature. Garrity and O'Toole (1994)

615

616 synchronized the flowering dates of 55 cultivars by clustering genotypes and by planting date respective of their cycle duration (based on previous data). In contrast, Lilley and Fukai (1994) triggered water deficit at a single fixed time after PI had occurred for all materials. In the same line, Subashri et al. (2009) used the same date for establishing the water deficit accepting some slight differences in earliness within a set of near genetic materials. Another time-consuming option implemented by Sellamuthu et al. (2011) is to regularly dissect extra plants and withhold irrigation when $50 \%$ of the studied genetic population is at PI, but with the high probability of not impacting the reproductive traits with the same intensity in all materials. Practically, it is proposed here to control the genotype development upstream and downstream by: (1) using PQ to better estimate the development rate of genotypes across a large range of environments, (2) conducting an initial trial for flowering time observation and clustering genotypes with respect to their crop duration, (3) running the main trial with distinct sowing dates respective of genotype clusters, (4) monitoring Haun Index all along the experiment in order to identify a posteriori the actual dates of PI and the genotype traits effectively affected by water deficit, that can be statistically compared for water deficit tolerance.

\section{Stability of water deficit response through contrasted climate conditions}

Comparing plant growth in favorable water conditions between the two sites was the first step to overcome before analyzing the response of genotypes to water deficit. The sites were discriminated respective of temperatures and VPD which were lower in GC compared to Sitis, and of incoming radiation which was even reduced by $63 \%$ in GC. This led to a drastic reduction in plant growth rate, elongation rate and leaf appearance rate, in GC compared to Sitis. In compensation, cycle duration -in days and in thermal time- was 
638 longer in GC than in Sitis. Finally, no significant differences in plant biomass or plant height 639 between sites were observed, highlighting the existence of trade-offs between phenological 640 rates and duration. Thus, Cookson et al. (2005) observed in leaf of Arabidopsis thaliana that 641 initial expansion rate was negatively correlated to the duration of expansion. Using radiation 642 treatments, Chenu et al. (2005) also found an increase in duration along with a decrease in elongation rate under low radiation treatment, while Cookson and Granier (2006) observed that the trade-off was not complete. Oppositely, when Arabidopsis thaliana was submitted to water deficit, Aguirrezabal et al. (2006) found a complete compensation between the extended duration and the decrease in elongation rate, supporting our own results in rice when submitted to water deficit.

The contrasted climate conditions associated with the same intensity in water deficit provided here the appropriate framework to evaluate whether or not any detected relationships characterizing plant response to water deficit are strong enough to be valid in a large range of environments. In our study, considering that the trial in GC ended at heading, we considered the maintenance of the reproductive sink size (branch and spikelet number) as the best indicator of water deficit tolerance, since it guaranteed yield potential. By combining the two trials, the analysis showed that the variation of spikelet and branch number was apparently independent of the variation in elongation rate (Table 11), meaning that the maintenance of organ elongation cannot be related to the maintenance of 657 development of the reproductive organs. Nevertheless, at trial level, the global trend was not 658 validated and environment specific plant responses to water deficit were reported: the more 659 a genotype reduced internode elongation and increased soluble sugar content under water deficit, the more sink size (spikelet and branch number) was maintained in Sitis but reduced in GC (Figure 6). This observation is likely related to the difference in plant carbon availability. This emphasizes how much the response of these traits to water deficit is 
663 dependent on climate conditions, and how conclusions often have to be restricted to the

664

665

666

667

668

669

670

671

672

673

674

675

676

677

678

679

680

681

682

683

684

685

686

687 conditions under study.

Other correlations are conserved across the two conditions. This is the case with the reduction in elongation rate, highly associated here with an increase in soluble sugars: soluble sugar content in plant organs is widely reported as increasing in response to water deficit, because organ elongation is reduced before any effect on leaf photosynthesis is detected (Boyer 1970; Muller et al. 2011). Thus, the plant diminishing carbon demand leads to an accumulation of sugars in source leaf and sink organs, which in turn appears as a good indicator of stress perception. Equally, the decrease in elongation rate is highly correlated to phyllochron lengthening, generating a delay in panicle emergence, trait widely considered as indicative of plant sensitivity to water deficit (Garrity and O'Toole 1994; Boonjung and Fukai 1996b; Subashri et al. 2009; Sellamuthu et al. 2011; He and Serraj 2012; Sheoran et al. 2014; Swamy et al. 2017). This is confirmed in GC but not in Sitis. We hypothesize high VPD and radiation in Sitis - and the low radiation and VPD in GC- are responsible for the differential responses to water deficit across trials.

\section{Tolerance criteria and genotype performance}

Flag leaf width and internode 2 diameter reduction were tightly correlated to sink size (Total Branch Number and Spikelet Number) reduction in both trials, whereas most of the other traits under investigation were not. This could be associated with the size of the apical meristem. Matsushima (1966) form early highlighted a strong correlation between internode 1 thickness and spikelet number of the panicle. Likewise, Dingkuhn et al. (2015) and Adriani et al. (2016) observed a high positive correlation between flag leaf area and spikelet number of the panicle. Kobayasi et al. (2002) demonstrated with different nitrogen treatments the correlation between the apical dome diameter at panicle initiation and the number of branches and spikelets of the panicle. And comparing wild (Oryza Barthii) and 
domesticated (Oryza Glaberrima) African rice, Ta et al (2017) found in O. Glaberrimaa wider rachis meristem associated with a more branched panicle. In fact, correlations between apical meristem and leaf size were widely reported: according to Itoh et al. (2005), the apical meristem size increased with leaf rank, generating longer and wider leaves; Fiorani et al. (2000) observed leaf dimensions and elongation rate increased with meristem size; and Lacube et al. (2017) found in maize that meristem size drove leaf width. These results suggested that meristem size and activity conditioned morphogenesis (leaf dimension) and organogenesis (branch and spikelet number) of initiated organs. The maintenance of flag leaf width under water deficit is then an indicator of the apical meristem size maintenance at early stage of the reproductive phase and thus of the ability of the plant to maintain high branch and spikelet number on the panicle.

A comprehensive representation of tolerance to water deficit relies then on the relationship between variations in flag leaf width and in branch number, as shown in Figure 7. Here, the overall tolerance of Cirad 409 and the overall sensitivity of IAC 25 were reported. More, stem elongation rate was maintained with Cirad 409 under both climate conditions, supporting the sink theory, as expressed by (Tardieu et al. 2018). In addition, the response to water deficit of these two genotypes, as well as of HD 1-4 and Guarani, was consistent across trials, through contrasted conditions of incoming radiation and temperature, which highlighted the validity of this response over a large range of conditions. Oppositely, the response of the other two genotypes, EM IAC 165 and Cirad 392, was not consistent over the present climate conditions: these genotypes may be poorly adapted to low radiation, or to high temperatures and VPD.

Figure 7 -Relative variation of branch number and flag leaf width under water deficit.

\section{Conclusions}


The plants grown in the two contrasted environments under study displayed

713

714 phenological and morphological differences at the time when water deficit was applied. Considering these distinct initial status, plants reacted to water deficit with the same processes, but with different intensity according to radiation and VPD conditions: the increase in phyllochron, and in soluble sugar content in source and sink organs, were associated with the decrease in stem elongation rate. Across both environments, this unique response did not have the same impact on the performance of yield components (branch and spikelet number on the panicle) with respect to genotypes, and could explain why a genotype is adapted or not. This highlights the necessity to restrict the validity of results and interpretation to the conditions explored by the study.

One key methodological practice here during the reproductive phase was to identify elementary traits that are actually affected by the transient water deficit and to conduct phenotyping only on these traits. Considering the diversity within phenological age across genotypes during the reproductive phase, it was necessary for this purpose to map panicle initiation respective of each genotype. Also in this study, it was a central hypothesis to consider that the most tolerant genotypes were those minimizing the effect of the transient water deficit on growth processes.

The flag leaf width finally appeared as a key trait to detect tolerance in case of a water deficit occurring at the early and medium stages of the reproductive phase. In both environments tested in this study, flag leaf width reduction in response to water deficit was highly correlated with the reduction in branch and spikelet number in the panicle of the same tiller. The reduction in flag leaf width was already reported in the literature as being a solid indicator of the decrease in size and activity of the apical meristem. We emphasize here that other traits could also be used for screening for drought tolerance according to the exact timing of water stress, like the variation in the diameter of an internode or the peduncle. The 
737 advantage to target such "secondary traits" resides in their capacity (i) to quantify precisely

738 the genotype-based effect of water deficit and so to distinguish the stress response across

739 genotypes and (ii) to detect relevant QTLs, closer from the basic metabolic processes that

740 drive rice plant response to water deficit.

$741 \quad$ List of abbreviations

742 TPE: Target populations of environment

743 HFE: Highly favorable environment

744 FE: Favorable environment

745 LFE: Least favorable environment

746 QTL: Quantitative trait loci

747 PI: Panicle initiation

748 SITIS: Integrated System for Induced Treatment of Drought

749 PVC: Polyvinyl chloride

750 IRR: Fully irrigated

751 STR: Water stress

752 NPK: Nitrogen phosphorus ans potassium

753 FC: Field capacity

754 WP: Wilting point

755 FTSW: Fraction of transpirable soil water

756 T min: Minimal temperature

757 T max: Maximal temperature

758 Rad: Daily cumulated incident radiation

759 VPD: air vapor pressure deficit

760 Tb: Base temperatura

761 Topt1: Temperature optimum 1 
762 Topt2: Temperature optimum 2

763 HI: Haun Index

764 DAP: Days after planting

765 FLNb: Flag leaf number

766 RGR: Relative growth rate

767 GR: Growth rate

768 Exp.: Experiment

769 Trmnt: Treatment

770 IN: Internode

771 Max: Maximum

772 vs: versus

773 PCA: Principal component analysis

$774 \Delta$ GrowthRate: Relative variation of growth rate between IRR and ST treatments

$775 \Delta$ ElongRate: Relative variation of total elongation rate between IRR and ST treatments

$776 \Delta$ TillNb: Relative variation of total tiller number between IRR and ST treatments

$777 \Delta$ FLLength: Relative variation of total flag leaf length between IRR and ST treatments

$778 \Delta$ FLWidth: Relative variation of total flag leaf width between IRR and ST treatments

$779 \Delta$ IN2Length: Relative variation of total internode 2 length between IRR and ST treatments

$780 \Delta \mathrm{IN} 2 \mathrm{Width}$ : Relative variation of total2 width between IRR and ST treatments

$781 \Delta$ LeafTransp: Relative variation of total leaf transpiration between IRR and ST treatments

$782 \Delta$ FLSolSug: Relative variation of total flag leaf soluble sugars between IRR and ST

783 treatments

$784 \Delta$ FLStarch: Relative variation of total flag leaf starch between IRR and ST treatments

$785 \Delta \mathrm{IN} 2$ SolSug: Relative variation of total internode 2 soluble sugar between IRR and ST

786 treatments 
$787 \Delta \mathrm{IN} 2$ Starch: Relative variation of total internode 2 starch between IRR and ST treatments

$788 \Delta$ Phyllochron: Relative variation of total phyllochron between IRR and ST treatments

$789 \Delta$ TotalBranchNb: Relative variation of total branch number between IRR and ST

790 treatments

$791 \Delta$ SpikeletNb: Relative variation of total spikelet number between IRR and ST treatments

792 TillNb: Tiller number

793 FLLength: Flag leaf length

794 FLWidth: Flag leaf width

795 IN2Length: Internode 2 length

796 IN2Width: internode 2 width

797 TotalBranchNb: Total branch number

798 SpikeletNb: Spikelet number

799 ElongRate: Elongation rate

800 FLSolSug: Flag leaf soluble sugars content

801 FLStarch: Flag leaf starch content

802 IN2SolSug: Internode 2 soluble sugars content

803 IN2Starch: Internode 2 starch content

804 LeafTransp: Leaf transpiration rate

805 PQ: Photothermal quotient

806 Declarations

807 Ethics approval and consent to participate

808 Not applicable

809 Consent for publication

810 Not applicable

811 Availability of data and material 
812 All data generated or analysed during this study are included in this published article.

\section{Competing interests}

814 The authors declare that they have no competing interests

\section{Funding}

816 This research received funding 1) from Agropolis Foundation and Embrapa through the

817 DRYCE project for the experiments conducted with the japonica panel and 2) from Capes 818 for the scholarship of the first author.

\section{Authors' contributions}

820 APdC and TL coordinated the Dryce research project.IPdL, MdR, and APdC designed and 821 carried out the Sitis experiment in Goiania. IPdL, SR, MdR and TLdesigned and carried out the growth chamber experiment in Montpellier. ACV and AS performed non-structural carbohydrate measurements and their statistical analysis. IPdL and MdR, with help of FB and TL, performed the data analysis and interpretation.MdR, IPdL and TL wrote the paper,which was edited and approved by all co-authors.

\section{Acknowledgements}

827 The authors thank the Agropolis Foundation (France) and Embrapa (Brazil) for funding the bilateral DRYCE project and Capes (Brazil) for supporting Isabela's PhD scholarship. The authors would like to thank all the Embrapa staff who contributed to the experiment, with particular thanks to Cleicomar Gonçalves de Almeida for help in conducting the experiment in the Sitis platform. Finally, we would like thank to Lauriane Rouan and Denis Cornet (Cirad) for help in the statistical analyses.

\section{References}

Adriani DE, Lafarge T, Dardou A, Fabro A, Clément-Vidal A, Yahya A, Dingkuhn A,Luquet D (2016) The QTSN positive effect on panicle and flag leaf size of rice is associated with an early down-regulation of tillering. Front Plant Sci 6 (1197): 1-17. C(2006) Plasticity to soil water deficit in Arabidopsis Thaliana: Dissection of leaf 
development into underlying growth dynamic and cellular variables reveals invisible phenotypes. Plant Cell and Environ 29 (12): 2216-27.

Alou IN, Steyn JM, Annandale JG, Van der Laan M (2018) Growth, phenological, and yield response of upland rice (Oryza Sativa L. Cv. Nerica 4®) to water stress during different growth stages. AgricWater Manag 198: 39-52.

Baumont M, Parent B, Manceau L, Brown HE, Driever SM, Muller B, Martre P (2019) Experimental and modeling evidence of carbon limitation of leaf appearance rate for spring and winter wheat. J Exp Bot 70(9): 2449-62.

Boonjung H and Fukai S (1996a) Effects of soil water deficit at different growth stages on rice growth and yield under upland conditions. 1. Growth during drought. Field Crops Res 48(1): $37-45$.

Boonjung H and Fukai S (1996b) Effects of soil water deficit at different growth stages on rice growth and yield under upland conditions. 2. Phenology, biomass production and yield. Field Crops Res 48(1): 47-55.

Bouchabké O, Tardieu F, Simonneau T (2006) Leaf growth and turgor in growing cells of maize (Zea Mays L.) respond to evaporative demand under moderate irrigation but not in water-saturated soil. Plant, Cell and Environ 29(6): 1138-48.

Bouman BAM, Kropff MJ, Tuong TP, Wopereis MCS, ten Berge HFM, Van Laar HH (2001) Oryza 2000: modelling lowland rice. 235p IRRI Ed.

Boyer JS (1970) Leaf enlargement and metabolic rates in corn, soybean, and sunflower at various leaf water potentials. Plant Physiol 46(2): 233-35.

Chenu K, Franck N, Dauzat J, Barczi JF, Rey H, Lecoeur J (2005) Integrated responses of rosette organogenesis, morphogenesis and architecture to reduced incident light in Arabidopsis thaliana results in higher efficiency of light interception, Func Plant Biol 32(12): 1123.

Cock JH and Yoshida S (1972) Accumulation of 14C-labelled carbohydrate before flowering and its subsequent redistribution and respiration in the rice plant. Jap. J. of Crop Science 31(2): $226-234$

Cookson SJ, Van Lijsebettens M, Granier C (2005) Correlation between leaf growth variables suggest intrinsic and early controls of leaf size in Arabidopsis Thaliana. Plant, Cell and Environ 28(11): 1355-66.

Cookson SJ and Granier C (2006) Adynamic analysis of the shade-induced plasticity in Arabidopsis thaliana rosette leaf development reveals new components of the shadeadaptative response. Annals of Botany 97(3): 443-52.

Counce PA, Keisling TC, Andrew JM (2000) A uniform, objectives, and adaptive system for expressing rice development. Crop Sci 40(2): 436-43. 
Dingkuhn M, Ma Rebecca CL, Kumar U, Mendez KS, Collard B, Jagadish K, Singh RK, Padolina T, Malabayabas M, Torres E, Rebolledo MC, Manneh B, Sow A (2015) Improving yield potential of tropical rice: achieved levels and perspectives through improved ideotypes. Field Crops Res182: 43-59.

Dosio GAA, Tardieu F, Turc O (2011) Floret initiation, tissue expansion and carbon availability at the meristem of the sunflower capitulum as affected by water or light deficits. New Phytol 189(1): 94-105.

Fischer KS, Fukai S (2003) How rice responds to drought, in Breeding rice for droughtprone environments, Eds. Fischer KS, Lafitte R, Fukai S, Atlin G and Hardy B, IRRI

Fiorani, F, Beemster GTS, Bultynck L, Lambers H(2000) Can meristematic activity determine variation in leaf size and elongation rate among four poa species? A Kinematic study. Plant Physiol 124(2): 845-55.

Nicolás F, Vaast P, Génard M, Dauzat J (2006) Soluble sugars mediate sink feedback downregulation of leaf photosynthesis in field-grown Coffea Arabica. Tree Physiol 26(4): $517-$ 25 .

Garrity DP and O'Toole JC (1994) Screening rice for drought resistance at the reproductive phase. Field Crops Res 39(2-3): 99-110.

Gibon Y, Pyl ET, Sulpice R, Lunn JE, HÖhne M, GÜnther M, Stitt M (2009) Adjustment of growth, starch turnover, protein content and central metabolism to a decrease of the carbon supply when arabidopsis is grown in very short photoperiods. Plant, Cell and Environ 32(7): 859-74.

Haun, JR (1973) Visual quantification of wheat development. Agron J 65: 116-119

Hong H and Serraj R (2012) Involvement of peduncle elongation, anther dehiscence and spikelet sterility in upland rice response to reproductive-stage drought stress. Environ Expl Bot 75: 120-27.

Heinemann AB, Barrios-Perez C, Ramirez-Villegas J, Arango-Londoño D, Bonilla-Findji O, Medeiros JC, Jarvis A (2015) Variation and impact of drought-stress patterns across upland rice target population of environments in Brazil.” J Exp Bot 66(12): 3625-38.

Hojsgaard S, Halekoh U, Hojsgaard MS, MASS Imports (2019). "Package 'DoBy.'”

Islam MS and Morison JIL (1992) Influence of solar radiation and temperature on irrigated rice grain yield in Bangladesh. Field Crops Res 30(1-2): 13-28.

Itoh JI, Nonomura KI, Ikeda K, Yamaki S, Inukai Y, Yamagishi H, Kitano H, Nagato Y (2005) Rice plant development: from zygote to spikelet." Plant and Cell Physiol 46(1): 2347.

Jamieson, PD, Brooking IR, Porter JR, Wilson DR (1995) Prediction of leaf appearance in wheat: a question of temperature. Field Crops Res 41(1): 35-44. 
Jelihovschi EG, Faria JC, Allaman IB (2014) Scott Knott: A package for performing the Scott-Knott clustering algorithm in R. Vol. 15. SciELO Brasil.

Kobayasi K, Horie Y, Imaki T (2002) Relationship between apical dome diameter at panicle initiation and the size of panicle components in rice grown under different nitrogen conditions during the vegetative stage. Plant Prod Sci 5(1): 3-7.

Kumar A, Bernier J, Verulkar S, Lafitte HR, Atlin GN (2008) Breeding for drought tolerance: direct selection for yield, response to selection and use of drought-tolerant donors in upland and lowland-adapted populations. Field Crops Res 107(3): 221-31.

Kumar A, Dixit S, Ram T, Yadaw RB, Mishra KK, Mandal NP (2014) Breeding highyielding drought-tolerant rice: genetic variations and conventional and molecular approaches. J Exp Bot 65(21): 6265-78.

Kumar A, Sandhu N, Dixit S, Yadav S, Swamy BPM, Shamsudin NAA (2018) Markerassisted selection strategy to pyramid two or more QTLs for quantitative trait-grain yield under drought. Rice 11(1).

Kumar U, Laza MR, Soulié JC, Pasco R, Mendez KVS, Dingkuhn M (2017) Analysis and simulation of phenotypic plasticity for traits contributing to yield potential in twelve rice genotypes. Field Crops Res 202: 94-107.

Lacube S, Fournier C, Palaffre C, Millet EJ, Tardieu F, Parent B (2017) Distinct controls of leaf widening and elongation by light and evaporative demand in maize. Plant Cell and Environ 40(9): 2017-28.

Lafitte R, Blum A, Atlin G (2003) Using secondary traits to help identify drought-tolerant genotypes" in breeding rice for drought-prone environments, Eds. Fischer KS, Lafitte R, Fukai S, Atlin G and Hardy B, IRRI.

Lanceras JC, Jongdee GPB, Toojinda T (2004) Quantitative trait loci associated with drought tolerance at reproductive stage in rice Author(s): Lanceras JC, Pantuwan G, Jongdee B and Theerayut Published by: American Society of Plant Biologists (ASPB). Plant Physiol 135(1): 384-99.

Lilley JM and Fukai S (1994a) Effect of timing and severity of water deficit on four diverse rice cultivars I. rooting pattern and soil water extraction. Field Crops Res 37(3): 205-13.

Lilley, JM and Fukai S (1994b) Effect of timing and severity of water deficit on four diverse rice cultivars III. Phenological development, crop growth and grain yield. Field Crops Res 37(3): 225-34.

Luquet D, Dingkuhn M, Kim H, Tambour L, Clement-Vidal A (2006) EcoMeristem, a model of morphogenesis and competition among sinks in rice. 1. Concept, validation and sensitivity analysis. Funct Plant Biol 33(4): 309-23. 
Luquet, D, Clément-Vidal A, Fabre D, This D, Sonderegger N, Dingkuhn M (2008) Orchestration of transpiration, growth and carbohydrate dynamics in rice during a dry-down cycle. Funct Plant Biol 35(8): 689.

Matsuo T and Hoshikawa K (1993) Science of the rice plant volume one: morphology. 686p. Food and Agriculture Policy Research Center, Tokyo Ed.

Matsushima S (1966) Crop science in rice: theory of yield determination and its application. Fuji, Tokyo.

De Mendiburu F (2014) Agricolae: statistical procedures for agricultural research. R Package Version 1(1).

MulleR B, Pantin F, Génard M, Turc O, Freixes S, Piques M, Gibon Y (2011) Water deficits uncouple growth from photosynthesis, increase c content, and modify the relationships between c and growth in sink organs. J Exp Bot 62(6): 1715-29.

Nemoto K, Morita S, Baba T (1995) Shoot and root development in rice related to the phyllochron. Crop Sci 35(1): 24-29

O'Toole JC and Namuco OS (1983) Role of panicle exertion in water stress induced sterility. Crop Sci. 23(6): 1093-1097

Pantin, F, Simonneau T, Rolland G, Dauzat M, Muller B (2011) Control of leaf expansion: A developmental switch from metabolics to hydraulics. Plant Physiol 156(2): 803-15.

Pantin F, Simonneau T, Muller B (2012) Coming of leaf age: Control of growth by hydraulics and metabolics during leaf ontogeny. New Phytol 196(2): 349-66.

Rebolledo, MC, Dingkuhn M, Clément-Vidal A, Rouan L, Luquet D (2012) Phenomics of rice early vigour and drought response: Are sugar related and morphogenetic traits relevant? Rice 5(1):1-15.

de Raissac M (1992) L'utilisation des carbohydrates de réserve et son incidence sur la production chez le riz. Agronomie Tropicale 46 (2): 97-105

Sandhu N, Dixit S, Swamy BPM, Raman A, Kumar S, Singh SP, Yadaw RB, Singh ON, Reddy JN, Anandan A, Yadav S, Venkataeshwarllu C, Henry A, Verulkar S, Mandal NP, Ram T, Badri J, Vikram P, Kumar A (2019) Marker assisted breeding to develop multiple stress tolerant varieties for flood and drought prone areas. Rice 12(1).

Sellamuthu R, Liu GF, Ranganathan CB, Serraj R (2011) Genetic analysis and validation of quantitative trait loci associated with reproductive-growth traits and grain yield under drought stress in a doubled haploid line population of rice (Oryza Sativa L.). Field Crops Res 124(1): 46-58.

Serraj R, Kumar A, McNally KL, Slamet-Loedin I, Bruskiewich R, Mauleon R, Cairns J, Hijmans RJ (2009) Chapter 2 Improvement of Drought Resistance in Rice. Vol. 103. 1st ed. Elsevier Inc. 
Serraj, R, McNally KL, Slamet-Loedin I, Kohli A, Haefele SM, Atlin H, Kumar A (2011) Drought resistance improvement in rice: an integrated genetic and resource management strategy. Plant ProdSci 14(1): 1-14.

Sharkey TD (2019) Is triose phosphate utilization important for understanding photosynthesis. J Exp Bot 70(20): 5521-25.

Sheoran, IS, Koonjul P, Attieh J,Saini HS (2014) Water-stress-induced inhibition of $\alpha$ tubulin gene expression during growth, and its implications for reproductive success in rice. Plant Physiol Bioch 80: 291-99.

Siband P, Wey J, Oliver R, Letourmy P, Manichon H (1999) Analysis of the yield of two groups of tropical maize cultivars. Varietal characteristics, yield potentials, optimum densities. Agronomie 19(5):379-94.

Sinclair TR and Ludlow MM (1986) Influence of soil water supply on the plant water balance of four tropical grain legumes. Funct Plant Biol 13(3):329-41.

Subashri M, Robin S, Vinod KK, Rajeswari S, Mohanasundaram K, Raveendran TS (2009) Trait identification and qtl validation for reproductive stage drought resistance in rice using selective genotyping of near flowering RILs. Euphytica 166(2): 291-305.

Swamy BPM, Shamsudin NAA, Rahman SNA, Mauleon R, Ratnam W, Cruz MTS, Kumar A(2017) Association mapping of yield and yield-related traits under reproductive stage drought stress in rice (Oryza Sativa L.). Rice 10(1).

Ta KN, Adam H, Staedler YM, Schönenberger J, Harrop T, Tregear J, Do NV, Gantet P, Ghesquière A, Jouannic S (2017) Differences in meristem size and expression of branching genes are associated with variation in panicle phenotype in wild and domesticated african rice. Evo Devo 8(1): 1-14.

Tardieu F (2005) Plant tolerance to water deficit: physical limits and possibilities for progress. C R Geosci 337(1-2): 57-67.

Tardieu F, Simonneau T,Muller B (2018) The physiological basis of drought tolerance in crop plants: a scenario-dependent probabilistic approach. Annu Rev Plant Biol 69(1).

Wey J, Oliver R, Manichon H, Siband P (1998) Analysis of local limitations to maize yield under tropical conditions. Agronomie 18(8-9): 545-61.

Wickham H (2016). Ggplot2: Elegant Graphics for Data Analysis. Springer. 
Table 6 - Impact of water deficit on reproductive phase processes in Sitis.

\begin{tabular}{|c|c|c|c|c|c|c|c|c|c|c|}
\hline \multirow[b]{3}{*}{ Genotypes } & \multicolumn{10}{|c|}{$\%$ of time process affected by water deficit } \\
\hline & \multicolumn{10}{|c|}{ SITIS } \\
\hline & $\begin{array}{c}\text { Panicle } \\
\text { primordium } \\
\text { formation } \\
\end{array}$ & $\begin{array}{c}\text { Flag leaf } \\
\text { formation }\end{array}$ & $\begin{array}{c}\text { Lower } \\
\text { Internode } \\
\text { elongation }\end{array}$ & $\begin{array}{l}\text { Branching I } \\
\text { formation }\end{array}$ & $\begin{array}{l}\text { Branching II } \\
\text { formation }\end{array}$ & $\begin{array}{c}\text { Internode } 2 \\
\text { elongation }\end{array}$ & $\begin{array}{c}\text { Spikelet } \\
\text { formation }\end{array}$ & $\begin{array}{c}\text { Internode } 1 \\
\text { elongation }\end{array}$ & $\begin{array}{c}\text { Pollen } \\
\text { viability }\end{array}$ & $\begin{array}{l}\text { Peduncle } \\
\text { elongation }\end{array}$ \\
\hline CIRAD 409 & 0 & 0 & 0 & 0 & 0 & 0 & 73 & 89 & 100 & 100 \\
\hline HD 1-4 & 0 & 0 & 0 & 23 & 33 & 33 & 73 & 100 & 100 & 100 \\
\hline CIRAD 392 & 0 & 0 & 0 & 30 & 38 & 38 & 94 & 100 & 100 & 100 \\
\hline IAC 25 & 0 & 0 & 0 & 30 & 38 & 38 & 94 & 100 & 100 & 100 \\
\hline EM IAC 165 & 0 & 0 & 0 & 36 & 44 & 44 & 94 & 100 & 100 & 100 \\
\hline GUARANI & 0 & 0 & 0 & 45 & 63 & 63 & 100 & 100 & 100 & 100 \\
\hline
\end{tabular}

Table 7 - Impact of water deficit on reproductive phase processes in Growth Chamber.

\begin{tabular}{|c|c|c|c|c|c|c|c|c|c|c|}
\hline \multirow[b]{3}{*}{ Genotypes } & \multicolumn{10}{|c|}{$\%$ of time process affected by water deficit } \\
\hline & \multicolumn{10}{|c|}{ Growth chamber } \\
\hline & $\begin{array}{c}\text { Panicle } \\
\text { primordium } \\
\text { formation }\end{array}$ & $\begin{array}{c}\begin{array}{c}\text { Flag leaf } \\
\text { formation }\end{array} \\
\end{array}$ & $\begin{array}{c}\text { Lower } \\
\text { internode } \\
\text { elongation }\end{array}$ & $\begin{array}{l}\text { Branching I } \\
\text { formation }\end{array}$ & $\begin{array}{c}\text { Branching II } \\
\text { formation }\end{array}$ & $\begin{array}{c}\text { Internode } 2 \\
\text { elongation }\end{array}$ & $\begin{array}{c}\text { Spikelet } \\
\text { formation }\end{array}$ & $\begin{array}{c}\text { Internode } 1 \\
\text { elongation }\end{array}$ & $\begin{array}{c}\text { Pollen } \\
\text { viability }\end{array}$ & $\begin{array}{l}\text { Peduncle } \\
\text { elongation }\end{array}$ \\
\hline IAC 25 & 0 & 38 & 38 & 100 & 100 & 100 & 100 & 100 & 100 & 100 \\
\hline EM IAC 165 & 10 & 50 & 50 & 100 & 100 & 100 & 100 & 100 & 100 & 100 \\
\hline CIRAD 392 & 23 & 62 & 62 & 100 & 100 & 100 & 100 & 100 & 100 & 100 \\
\hline HD 1-4 & 44 & 69 & 69 & 100 & 100 & 100 & 100 & 100 & 100 & 100 \\
\hline GUARANI & 57 & 79 & 79 & 100 & 100 & 100 & 100 & 100 & 100 & 100 \\
\hline CIRAD 409 & 64 & 84 & 84 & 100 & 100 & 100 & 100 & 100 & 100 & 100 \\
\hline
\end{tabular}


Table 11 - Correlations matrix of the studied variables.

\begin{tabular}{|c|c|c|c|c|c|c|c|c|c|c|c|c|c|c|}
\hline Variables & $\begin{array}{l}\Delta \text { Growt } \\
\text { h rate }\end{array}$ & $\begin{array}{c}\Delta \text { Elong } \\
\text { rate }\end{array}$ & $\begin{array}{c}\Delta \text { Tiller } \\
\text { Nb }\end{array}$ & $\begin{array}{c}\Delta F L \\
\text { length }\end{array}$ & $\begin{array}{c}\Delta \mathrm{FL} \\
\text { width }\end{array}$ & $\begin{array}{c}\Delta I N 2 \\
\text { length }\end{array}$ & $\begin{array}{l}\Delta \mathrm{IN2} \\
\text { width }\end{array}$ & $\begin{array}{c}\Delta \text { LeafT } \\
\text { ransp }\end{array}$ & $\begin{array}{c}\Delta \text { FlagLe } \\
\text { af } \\
\text { SolSug } \\
\end{array}$ & $\begin{array}{c}\Delta \text { Flag } \\
\text { LeafSt } \\
\text { arch } \\
\end{array}$ & $\begin{array}{c}\Delta I N 2 \\
\text { SolSug }\end{array}$ & $\begin{array}{c}\Delta \mathrm{IN} 2 \\
\text { Starch }\end{array}$ & $\Delta$ Phyllochron & $\begin{array}{c}\Delta \text { Total } \\
\text { BranchNb }\end{array}$ \\
\hline$\Delta$ GrowthRate & 1 & & & & & & & & & & & & & \\
\hline$\Delta$ ElongRate & 0.218 & 1 & & & & & & & & & & & & \\
\hline$\Delta$ TillNb & $0.455^{\circ}$ & -0.049 & 1 & & & & & & & & & & & \\
\hline$\Delta$ FLLength & -0.209 & -0.204 & -0.369 & 1 & & & & & & & & & & \\
\hline$\Delta$ FLWidth & -0.196 & -0.054 & -0.521 & $0.580 *$ & 1 & & & & & & & & & \\
\hline$\Delta$ IN2Length & 0.412 & $0.869 * * *$ & -0.129 & -0.301 & -0.050 & 1 & & & & & & & & \\
\hline$\Delta$ IN2Width & 0.149 & -0.001 & -0.498 & 0.435 & $0.712 * *$ & 0.266 & 1 & & & & & & & \\
\hline$\Delta$ LeafTransp & -0.188 & 0.291 & -0.419 & 0.131 & 0.044 & 0.438 & 0.396 & 1 & & & & & & \\
\hline$\Delta$ FLSolSug & -0.188 & $-0.659 *$ & -0.329 & 0.447 & 0.220 & $-0.594 *$ & 0.239 & -0.194 & 1 & & & & & \\
\hline$\Delta$ FLStarch & 0.222 & $0.686 *$ & -0.425 & -0.141 & 0.329 & $0.769 * *$ & 0.482 & 0.402 & -0.195 & 1 & & & & \\
\hline$\Delta I N 2 S o l S u g$ & 0.287 & $-0.518^{\circ}$ & -0.009 & 0.151 & -0.052 & -0.209 & 0.458 & 0.097 & $0.593 *$ & -0.055 & 1 & & & \\
\hline$\Delta$ IN2Starch & 0.203 & 0.453 & 0.218 & -0.254 & -0.322 & 0.434 & 0.063 & 0.217 & -0.221 & 0.370 & 0.305 & 1 & & \\
\hline$\Delta$ Phyllochron & 0.045 & $-0.759 * *$ & -0.073 & -0.117 & -0.006 & -0.401 & 0.193 & -0.124 & 0.376 & -0.318 & $0.644 *$ & -0.220 & 1 & \\
\hline$\Delta$ Total BranchNb & -0.178 & 0.047 & $-0.511^{\circ}$ & $0.730 * *$ & $0.736 * *$ & 0.032 & $0.728 * *$ & $0.526^{\circ}$ & 0.207 & 0.375 & 0.193 & 0.025 & -0.136 & 1 \\
\hline$\Delta$ SpikeletNb & -0.160 & 0.209 & -0.470 & $0.712 * *$ & 0.703* & 0.155 & 0.619* & 0.578* & 0.071 & 0.413 & -0.036 & -0.064 & -0.331 & $0.945 * * *$ \\
\hline
\end{tabular}

${ }^{\circ}:$ Significant at $\mathrm{P}<0.1 ; *$ : significant at $\mathrm{P}<0.05 ; * *$ : significant at $\mathrm{P}<0.01 ;$ and $* * *$ : significant at $\mathrm{P}<0.001$. 
Table 12 - Response index in Sitis and in Growth Chamber experiments for all studied traits and genotypes.

\begin{tabular}{|c|c|c|c|c|c|c|c|c|c|c|c|c|}
\hline \multirow[b]{2}{*}{ Traits } & \multicolumn{2}{|c|}{ CIRAD 392} & \multicolumn{2}{|c|}{ CIRAD 409} & \multicolumn{2}{|c|}{ EM IAC165 } & \multicolumn{2}{|c|}{ GUARANI } & \multicolumn{2}{|c|}{ HD1-4 } & \multicolumn{2}{|c|}{ IAC25 } \\
\hline & SITIS & $\begin{array}{c}\text { Growth } \\
\text { Chamber }\end{array}$ & SITIS & $\begin{array}{c}\text { Growth } \\
\text { Chamber }\end{array}$ & SITIS & $\begin{array}{c}\text { Growth } \\
\text { Chamber }\end{array}$ & SITIS & $\begin{array}{c}\text { Growth } \\
\text { Chamber }\end{array}$ & SITIS & $\begin{array}{c}\text { Growth } \\
\text { Chamber }\end{array}$ & SITIS & $\begin{array}{c}\text { Growth } \\
\text { Chamber }\end{array}$ \\
\hline$\Delta$ TillNb & $-0.12^{\mathrm{ns}}$ & $0.13^{\text {ns }}$ & $0.04^{\mathrm{ns}}$ & $-0.26^{\mathrm{ns}}$ & $-0.10^{\mathrm{ns}}$ & $0.26^{\mathrm{ns}}$ & $-0.13^{\mathrm{ns}}$ & $0.06^{\mathrm{ns}}$ & $-0.07^{\mathrm{ns}}$ & $-0.11^{\mathrm{ns}}$ & $-0.27 *$ & $-0.06^{\mathrm{ns}}$ \\
\hline$\Delta$ Plant Height (mm) & $-0.26 * *$ & $-0.23 * *$ & $-0.03^{\mathrm{ns}}$ & $0.02^{\mathrm{ns}}$ & $-0.28 * *$ & $-0.18 * *$ & $-0.21 * *$ & $-0.12 *$ & $-0.15^{*}$ & $-0.19 * *$ & $-0.20 * *$ & $-0.19 * *$ \\
\hline$\Delta$ Plant Biomass (g) & $-0.14^{\mathrm{ns}}$ & $-0.40^{* *}$ & $-0.01^{\mathrm{ns}}$ & $0.04^{\mathrm{ns}}$ & $-0.16^{\mathrm{ns}}$ & $0.31^{*}$ & $-0.19^{\text {ns }}$ & $-0.15^{\mathrm{ns}}$ & $-0.21^{*}$ & $-0.36^{*}$ & $-0.38 * *$ & $-0.21^{\mathrm{ns}}$ \\
\hline$\Delta$ Growth Rate (g.day $\left.{ }^{-1}\right)$ & -0.15 & $-0.39 * *$ & $-0.01^{\mathrm{ns}}$ & $0.03^{\mathrm{ns}}$ & $-0.16^{\mathrm{ns}}$ & $0.41 *$ & $-0.19^{\text {ns }}$ & $-0.17^{\mathrm{ns}}$ & $-0.21 *$ & $-0.38^{*}$ & $-0.38 * *$ & $-0.21^{\mathrm{ns}}$ \\
\hline$\Delta$ FLLength $(\mathrm{mm})$ & $0.16^{\mathrm{ns}}$ & $-0.17^{\mathrm{ns}}$ & $0.03^{\mathrm{ns}}$ & $-0.15^{\mathrm{ns}}$ & $-0.16^{\mathrm{ns}}$ & $-0.25^{\mathrm{ns}}$ & 0.00 & $-0.18^{\mathrm{ns}}$ & $-0.02^{\mathrm{ns}}$ & $-0.13^{\text {ns }}$ & $-0.09^{\mathrm{ns}}$ & $-0.16^{\mathrm{ns}}$ \\
\hline$\Delta$ FLWidth (mm) & $0.08^{\mathrm{ns}}$ & 0.00 & $0.04^{\mathrm{ns}}$ & $0.07^{\mathrm{ns}}$ & $0.03^{\text {ns }}$ & $-0.17 * *$ & $-0.02^{\mathrm{ns}}$ & $-0.12^{\text {ns }}$ & $-0.07^{\mathrm{ns}}$ & $-0.11^{\mathrm{ns}}$ & $-0.03^{\text {ns }}$ & $-0.05^{\mathrm{ns}}$ \\
\hline$\Delta \mathrm{IN} 2$ Length $(\mathrm{mm})$ & $-0.39 *$ & $-0.34 *$ & $-0.04^{\mathrm{ns}}$ & $0.21^{\mathrm{ns}}$ & $-0.32 *$ & $-0.12^{\mathrm{ns}}$ & $-0.26^{*}$ & $-0.06^{\mathrm{ns}}$ & $-0.27 *$ & $-0.13^{\mathrm{ns}}$ & $-0.22 *$ & $-0.28 * *$ \\
\hline$\Delta$ IN2Width (mm) & $-0.03^{\text {ns }}$ & $-0.18^{* *}$ & 0.00 & $0.01^{\mathrm{ns}}$ & $0.03^{\text {ns }}$ & $-0.17 * *$ & $-0.03^{\text {ns }}$ & $-0.09^{\text {ns }}$ & $-0.14^{*}$ & $-0.16^{* \mathrm{n}}$ & $-0.09^{\text {ns }}$ & $0.16^{* *}$ \\
\hline$\Delta$ TotalBranchNb & $0.09^{\text {ns }}$ & $-0.31 *$ & $-0.07^{\mathrm{ns}}$ & $-0.08^{\mathrm{ns}}$ & $-0.12^{\text {ns }}$ & $-0.46^{* *}$ & $-0.13^{\mathrm{ns}}$ & $-0.19^{\text {ns }}$ & $-0.23 *$ & $-0.17^{\mathrm{ns}}$ & $-0.31 * *$ & $-0.25^{\mathrm{ns}}$ \\
\hline$\Delta$ SpikeletNb & $0.06^{\mathrm{ns}}$ & $-0.28 *$ & $-0.01^{\mathrm{ns}}$ & $-0.03^{\text {ns }}$ & $-0.17 *$ & $-045 * *$ & $-0.19^{*}$ & $-0.24^{\mathrm{ns}}$ & $-0.17 *$ & $-0.10^{\mathrm{ns}}$ & $-0.33^{* *}$ & $-0.26^{*}$ \\
\hline$\Delta$ ElongRate $\left(\mathrm{mm}\right.$.day $\left.{ }^{-1}\right)$ & $-0.44^{* *}$ & $-0.34 * *$ & $-0.20^{\mathrm{ns}}$ & $-0.01^{\mathrm{ns}}$ & $-0.55^{* *}$ & $-0.33^{* *}$ & $-0.38^{* *}$ & $-0.17^{*}$ & $-0.31^{*}$ & $-0.26^{* *}$ & $-0.41 * *$ & $-0.28 * *$ \\
\hline$\Delta$ FLSolSug $\left(\mathrm{mg.g}^{-1}\right)$ & $0.90 * *$ & $0.26^{\mathrm{ns}}$ & $-0.02^{\mathrm{ns}}$ & $0.18^{\mathrm{ns}}$ & $0.82 * *$ & $0.27 *$ & $0.66^{* *}$ & $0.29 *$ & $0.97 * *$ & $0.06^{\mathrm{ns}}$ & $0.68 * *$ & $0.15^{\mathrm{ns}}$ \\
\hline$\Delta$ FLStarch $\left(\mathrm{mg} \mathrm{g}^{-1}\right)$ & $-0.18 * *$ & $-0.43^{\mathrm{ns}}$ & $-0.28 * *$ & $1.16^{\mathrm{ns}}$ & $-0.13^{\text {ns }}$ & $-0.38^{\mathrm{ns}}$ & $-0.34 * *$ & $0.14^{\mathrm{ns}}$ & $-0.27 * *$ & $-0.18^{\mathrm{ns}}$ & $-0.39 * *$ & $-0.37^{\mathrm{ns}}$ \\
\hline$\Delta$ IN2SolSug $\left(\mathrm{mg.g}^{-1}\right)$ & $1.48 * *$ & $-0.62 *$ & $0.08^{\mathrm{ns}}$ & $-0.02^{\mathrm{ns}}$ & $1.91^{* *}$ & $1.21 *$ & $1.10^{* *}$ & $1.40 *$ & $0.38^{\text {ns }}$ & $-0.04^{\mathrm{ns}}$ & $0.85^{* *}$ & $-0.35^{\text {ns }}$ \\
\hline$\Delta \mathrm{IN} 2 \mathrm{Starch}$ (mg.g-1) & $-0.06^{\mathrm{ns}}$ & $-0.34^{\mathrm{ns}}$ & $-0.01^{\mathrm{ns}}$ & $0.17^{\mathrm{ns}}$ & $-0.17^{\mathrm{ns}}$ & $0.09^{\mathrm{ns}}$ & $-0.26^{* *}$ & $1.47^{\mathrm{ns}}$ & $-0.17^{\mathrm{ns}}$ & $-0.19^{\text {ns }}$ & $-0.20^{*}$ & $-0.06^{\mathrm{ns}}$ \\
\hline$\Delta$ LeafTransp $\left(\mathrm{mmol} . \mathrm{m}^{-2} . \mathrm{s}^{-1}\right)$ & $-0.17^{\mathrm{ns}}$ & $-0.36^{* *}$ & $-0.05^{\mathrm{ns}}$ & $-0.05^{\mathrm{ns}}$ & $0.06^{\mathrm{ns}}$ & $-0.31 *$ & $-0.15^{\mathrm{ns}}$ & $-0.05^{\mathrm{ns}}$ & $-0.17 *$ & $0.15^{\mathrm{ns}}$ & $-0.20 *$ & $-0.25^{*}$ \\
\hline
\end{tabular}

Response index represents the relative variation of a trait between stressed and control treatments (see Mat 1 Meth); negative value means a reduction in stressed plants in relation with control

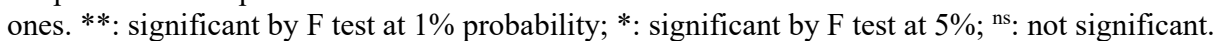




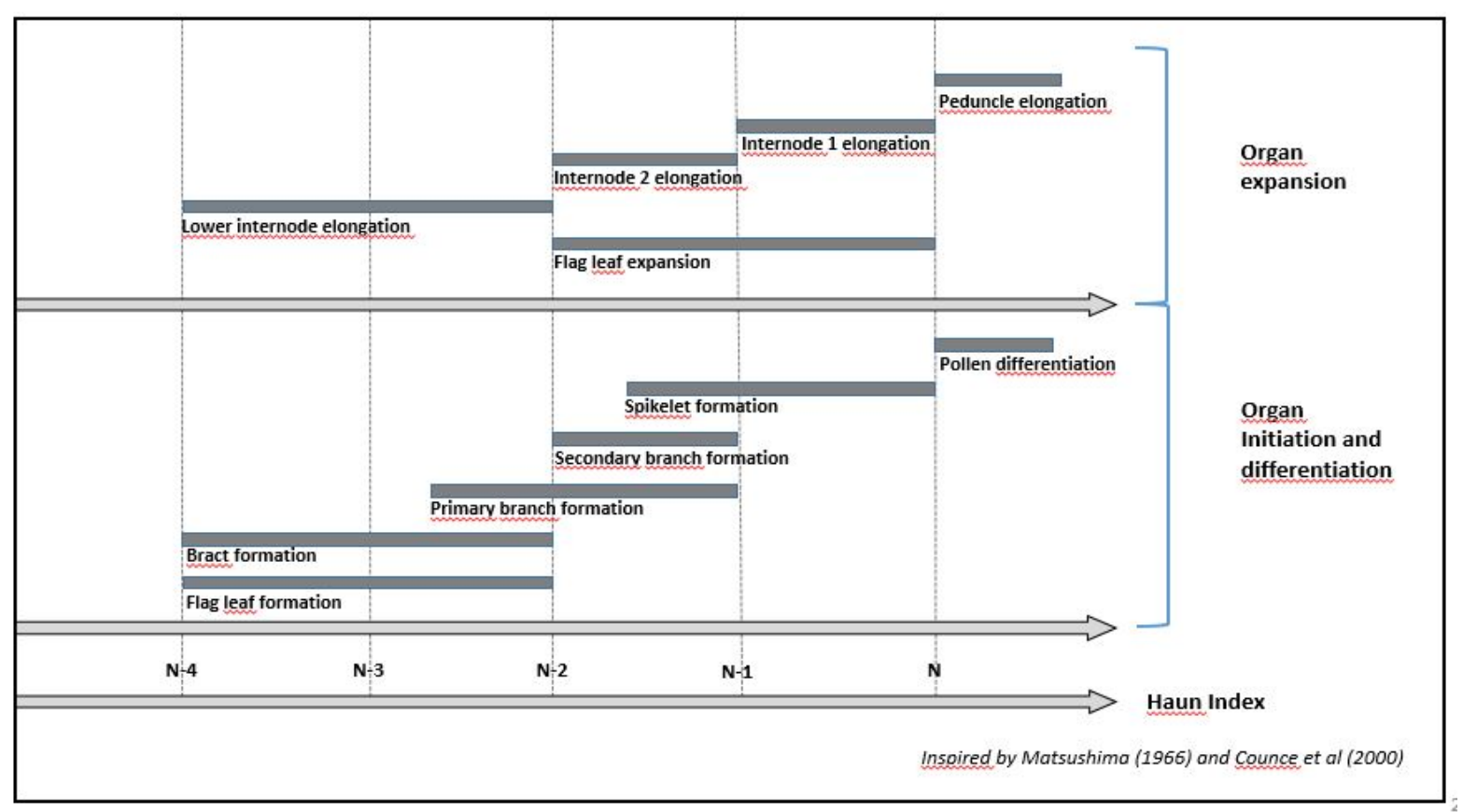

Figure 1- Timing of developmental processes during the reproductive phase in rice

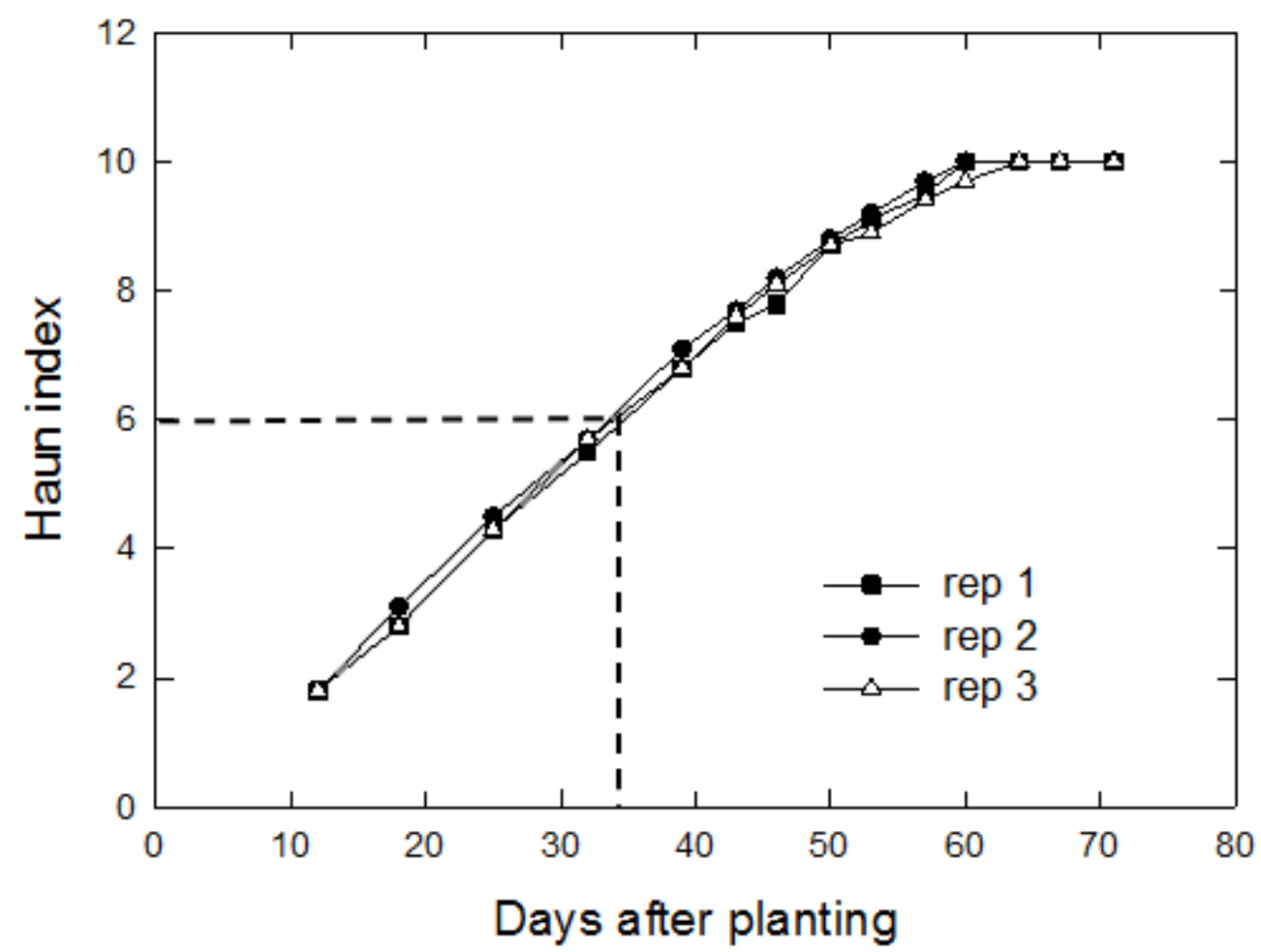

Figure 2 - Determination of the panicle initiation date on irrigated Cirad 409 in the growth chamber experiment 


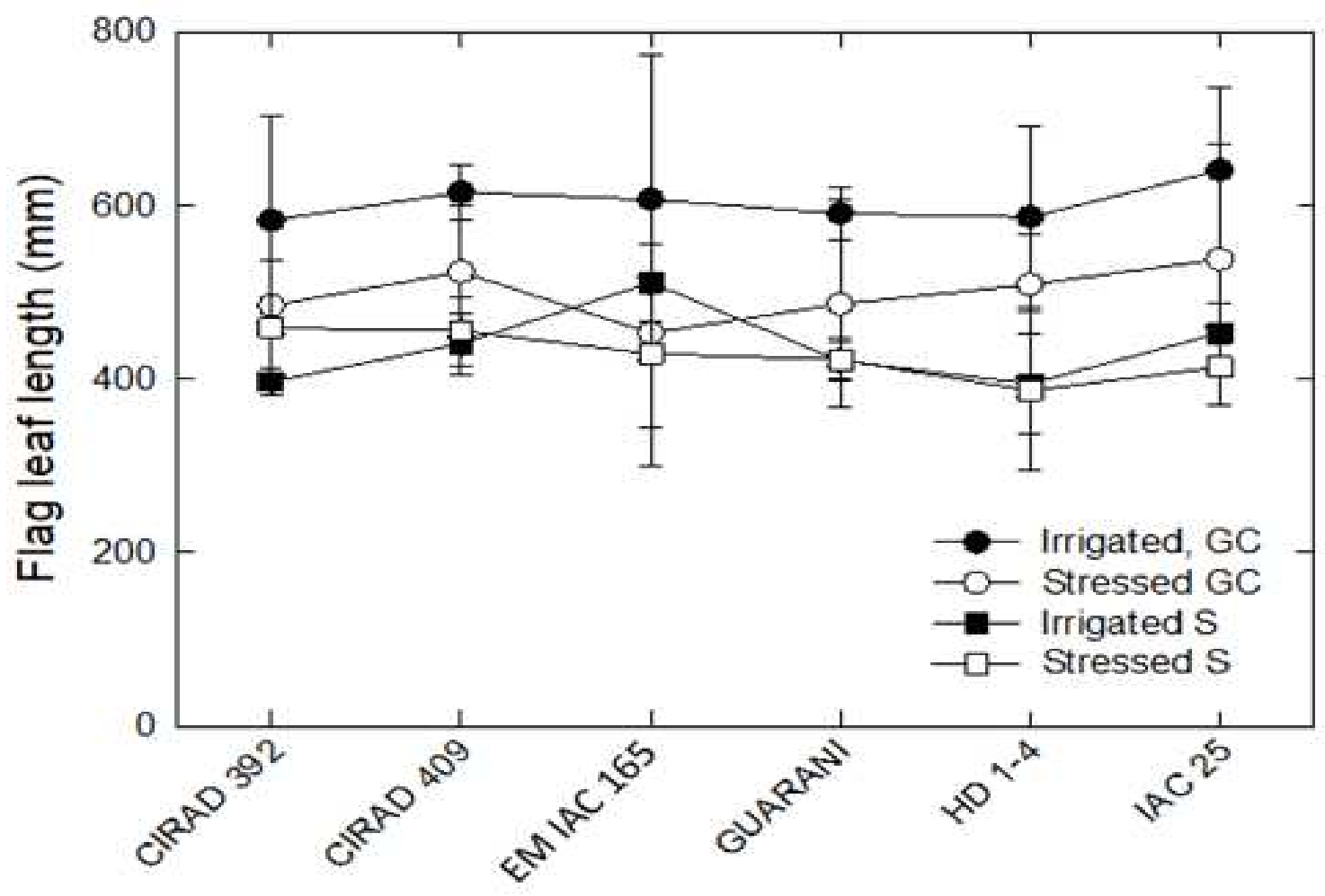

\section{Genotypes}

Figure 3 - Flag leaf length in relation with the experiments and water treatments. 


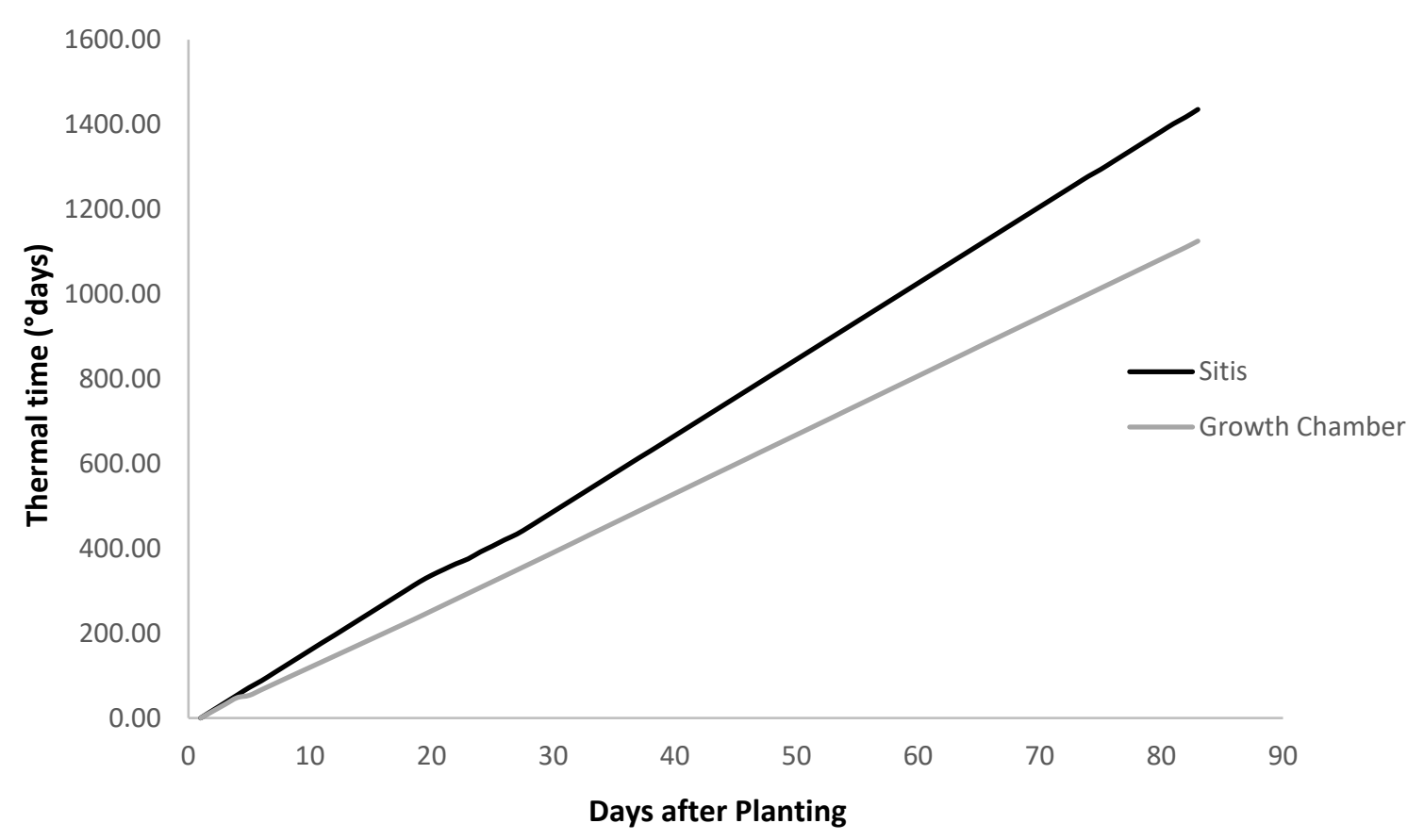

Figure 4 - Cumulated thermal time in Sitis and growth chamber experiments in function of calendar time.

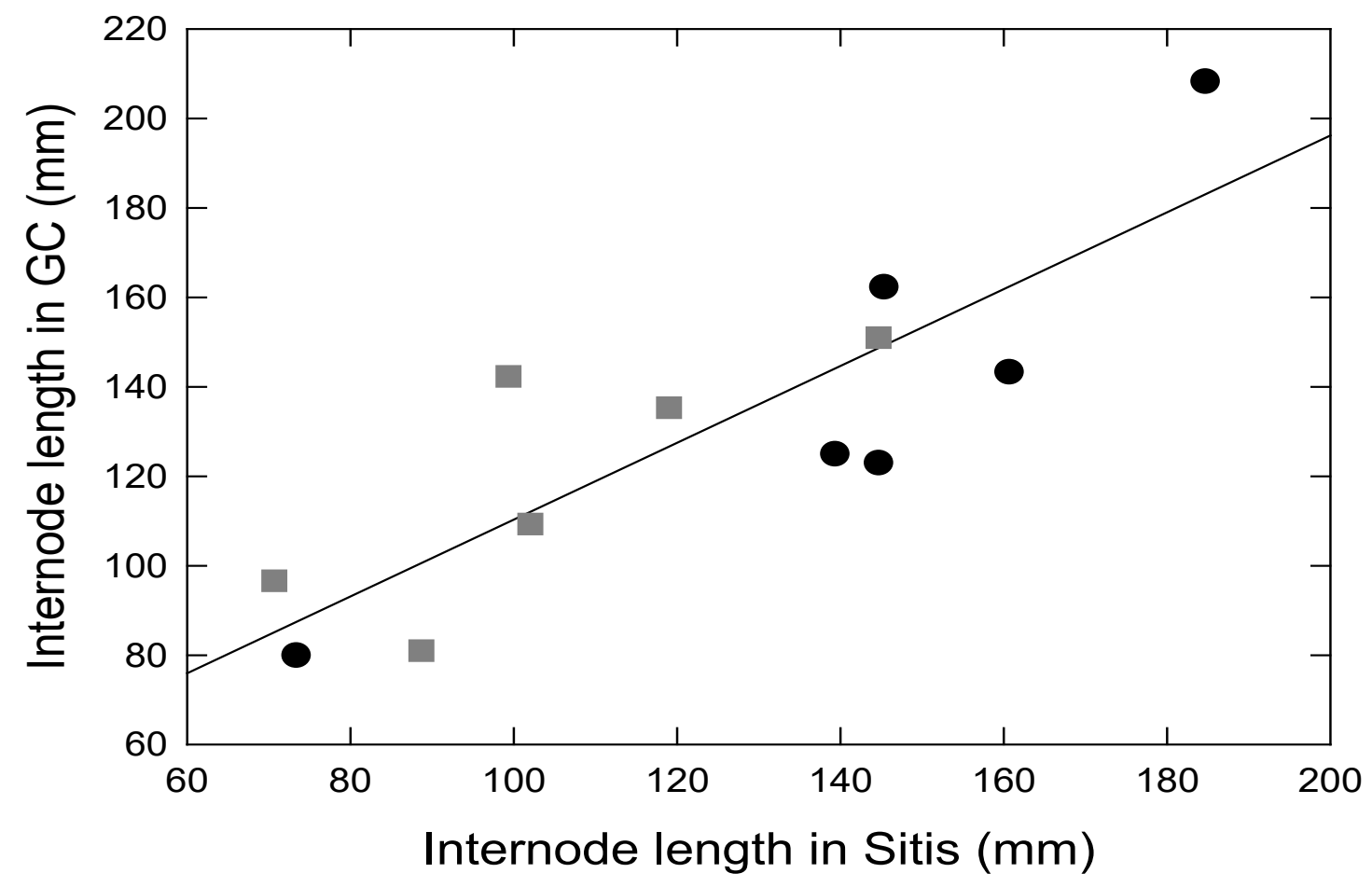

Figure 5 - Relationship between internode 2 length in Growth Chamber and Sitis experiments 

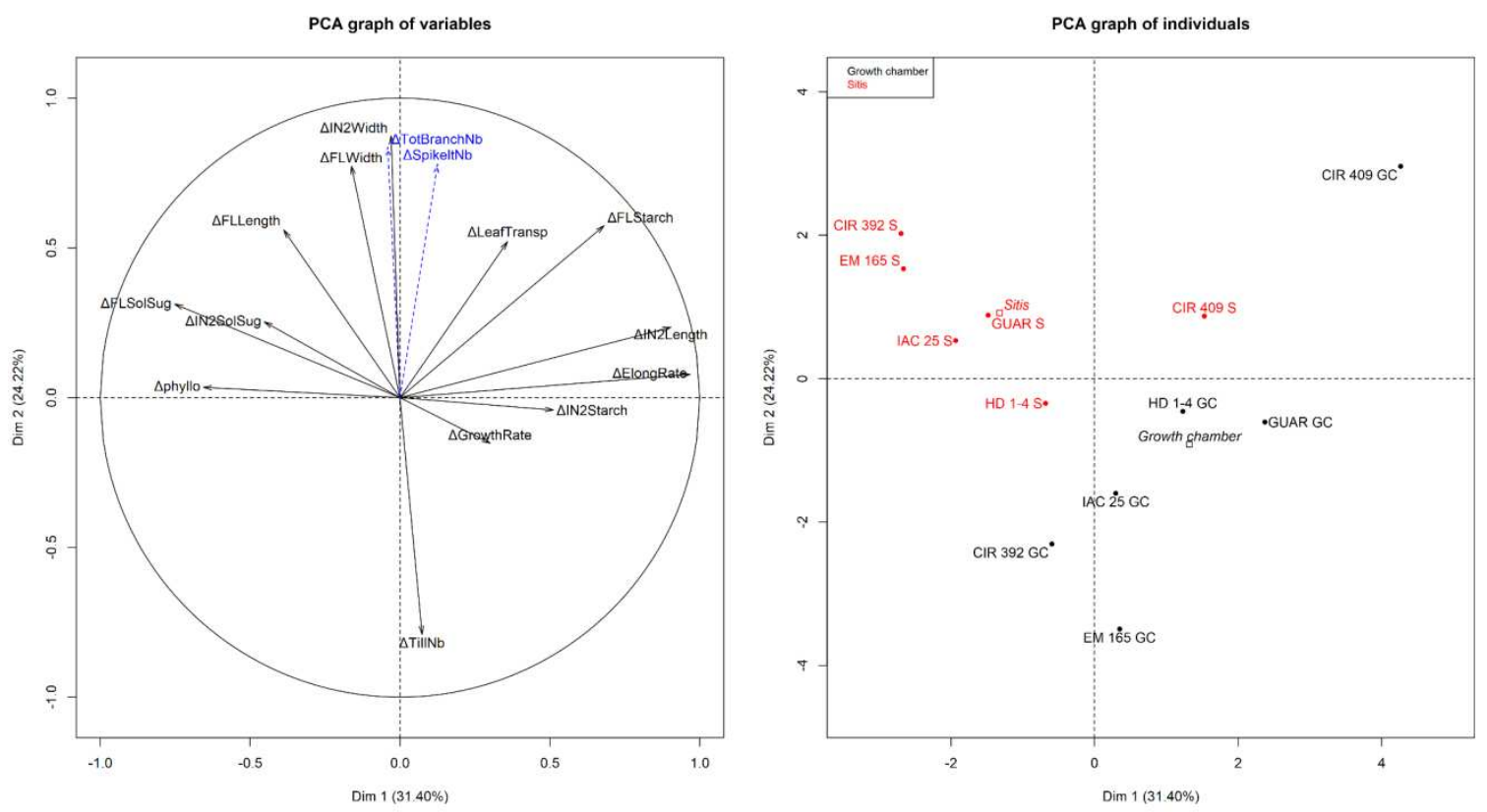

Figure 6 - Principal Component Analysis representation on the two first components of the response index.

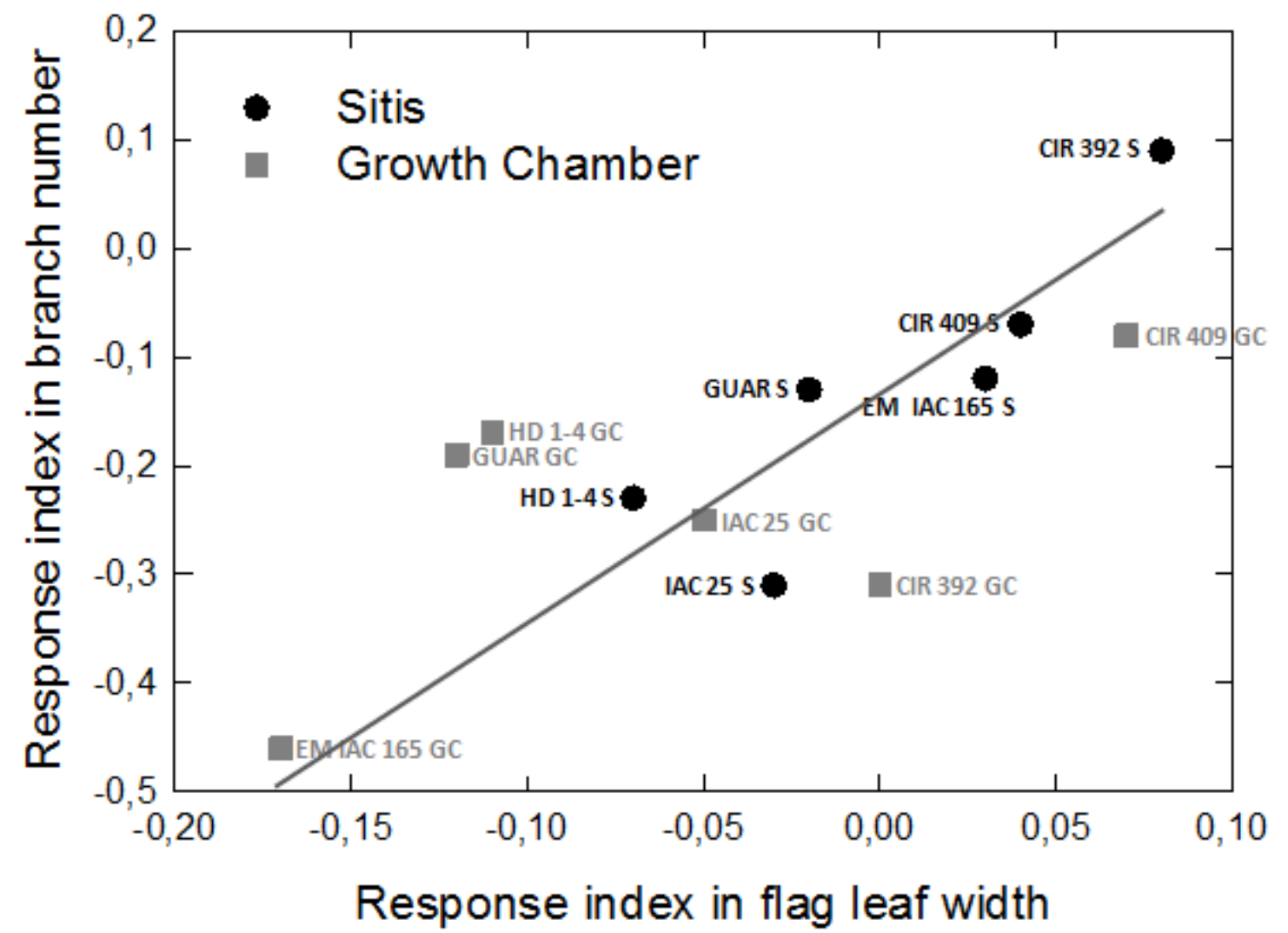

Figure 7 - Relative variation of branch number and flag leaf width under water deficit. 
Figures

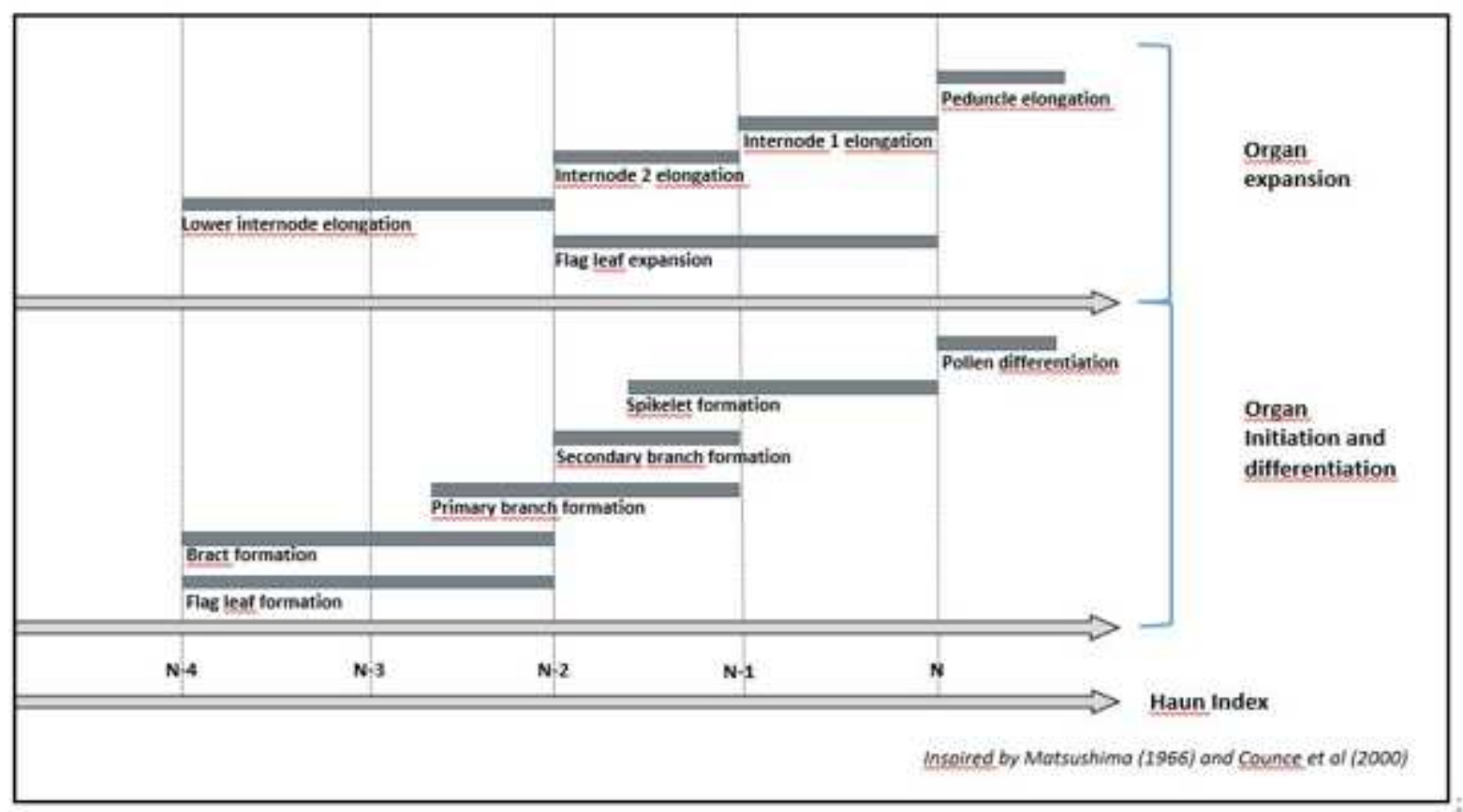

Figure 1

Timing of developmental processes during the reproductive phase in rice

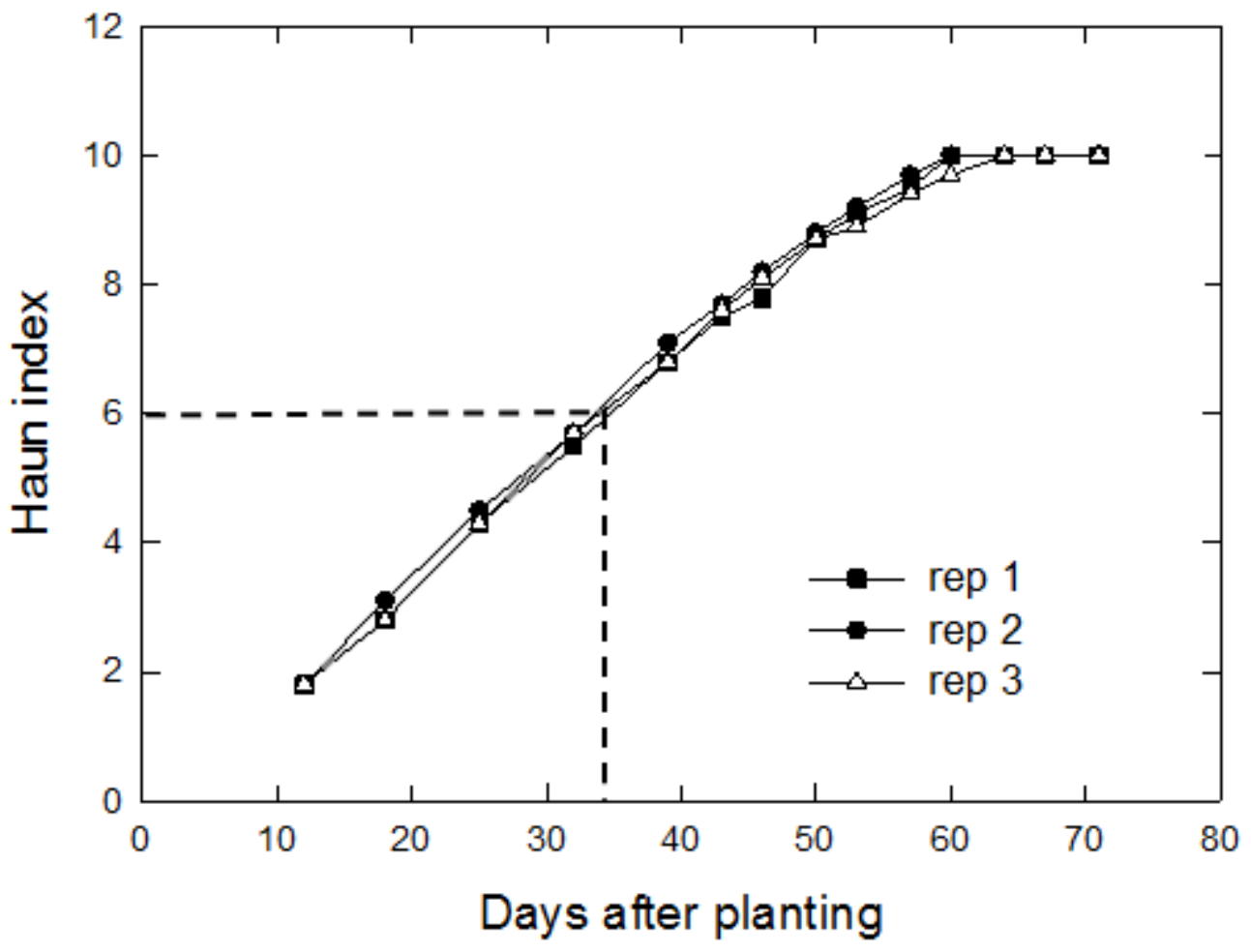

Figure 2

Determination of the panicle initiation date on irrigated Cirad 409 in the growth chamber experiment 


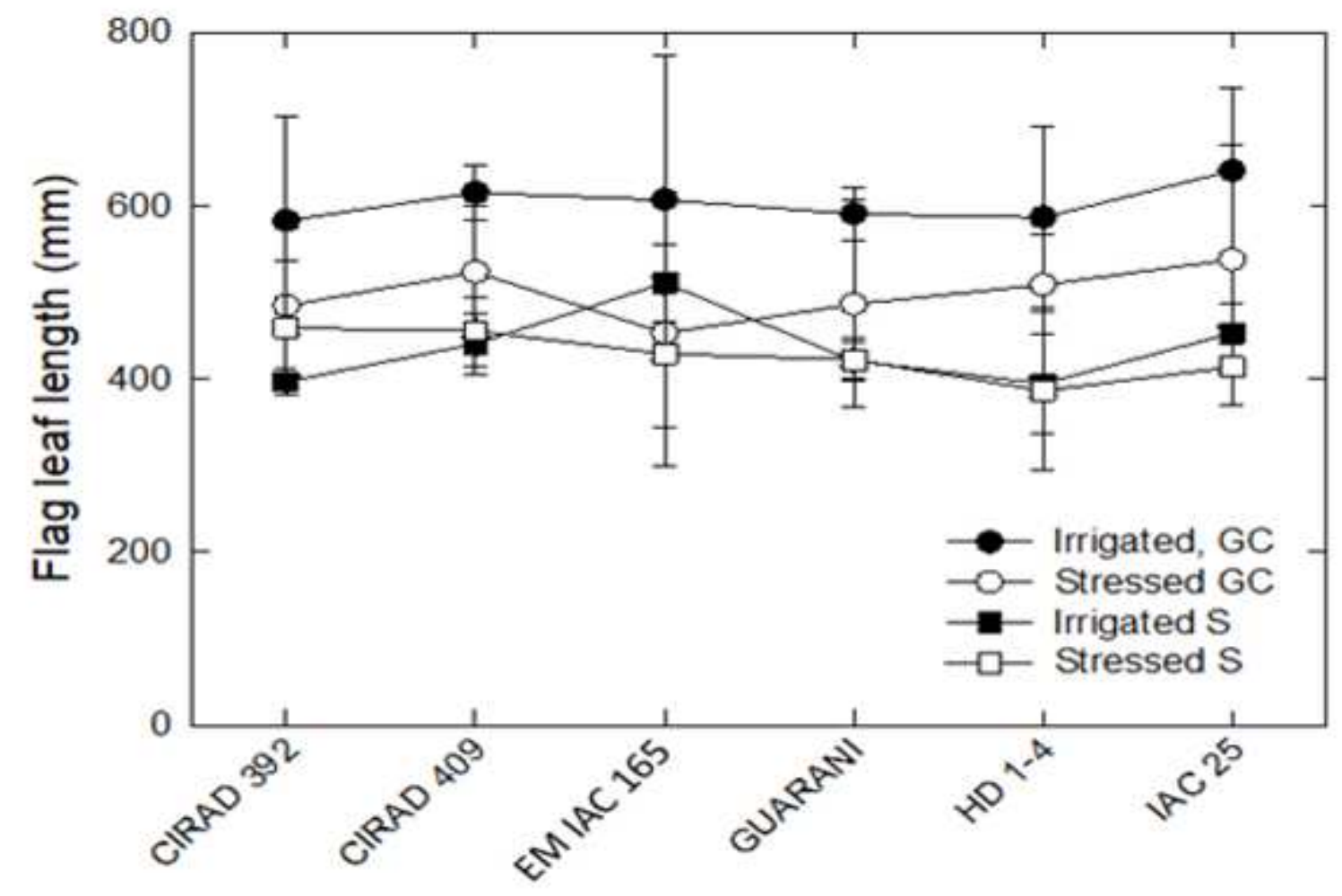

\section{Figure 3}

Flag leaf length in relation with the experiments and water treatments.

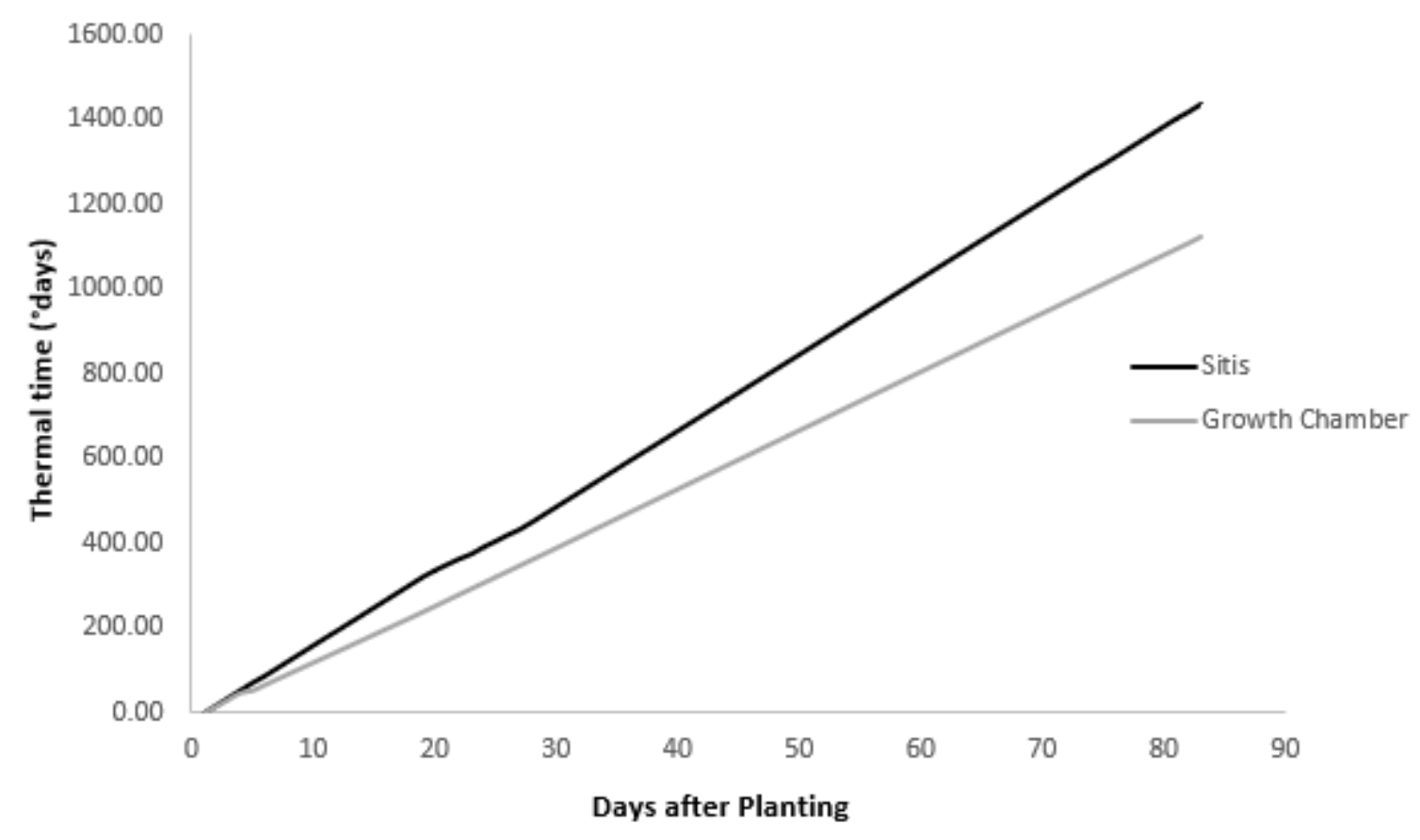

Figure 4

Cumulated thermal time in Sitis and growth chamber experiments in function of calendar time. 


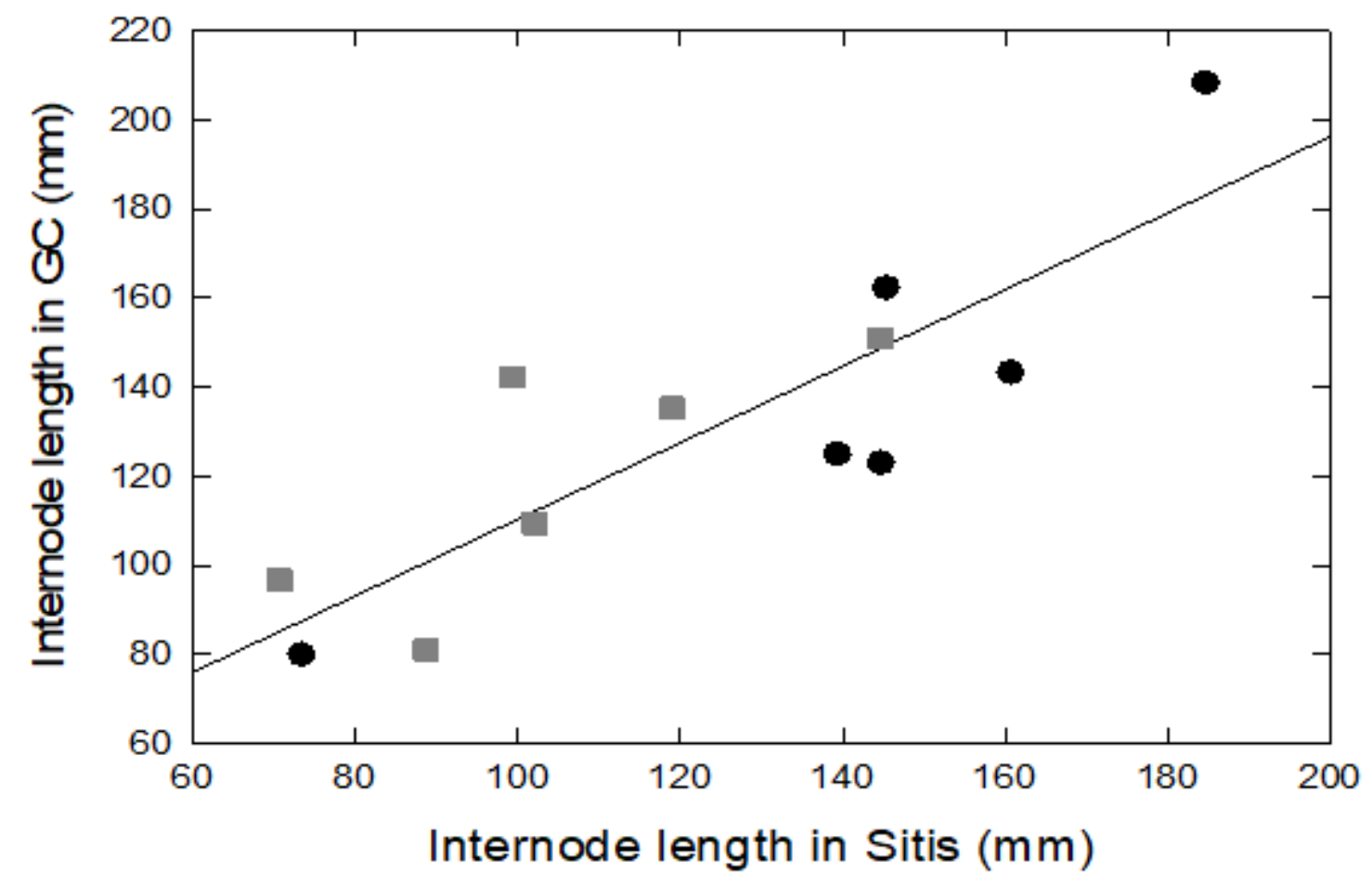

Figure 5

Relationship between internode 2 length in Growth Chamber and Sitis experiments
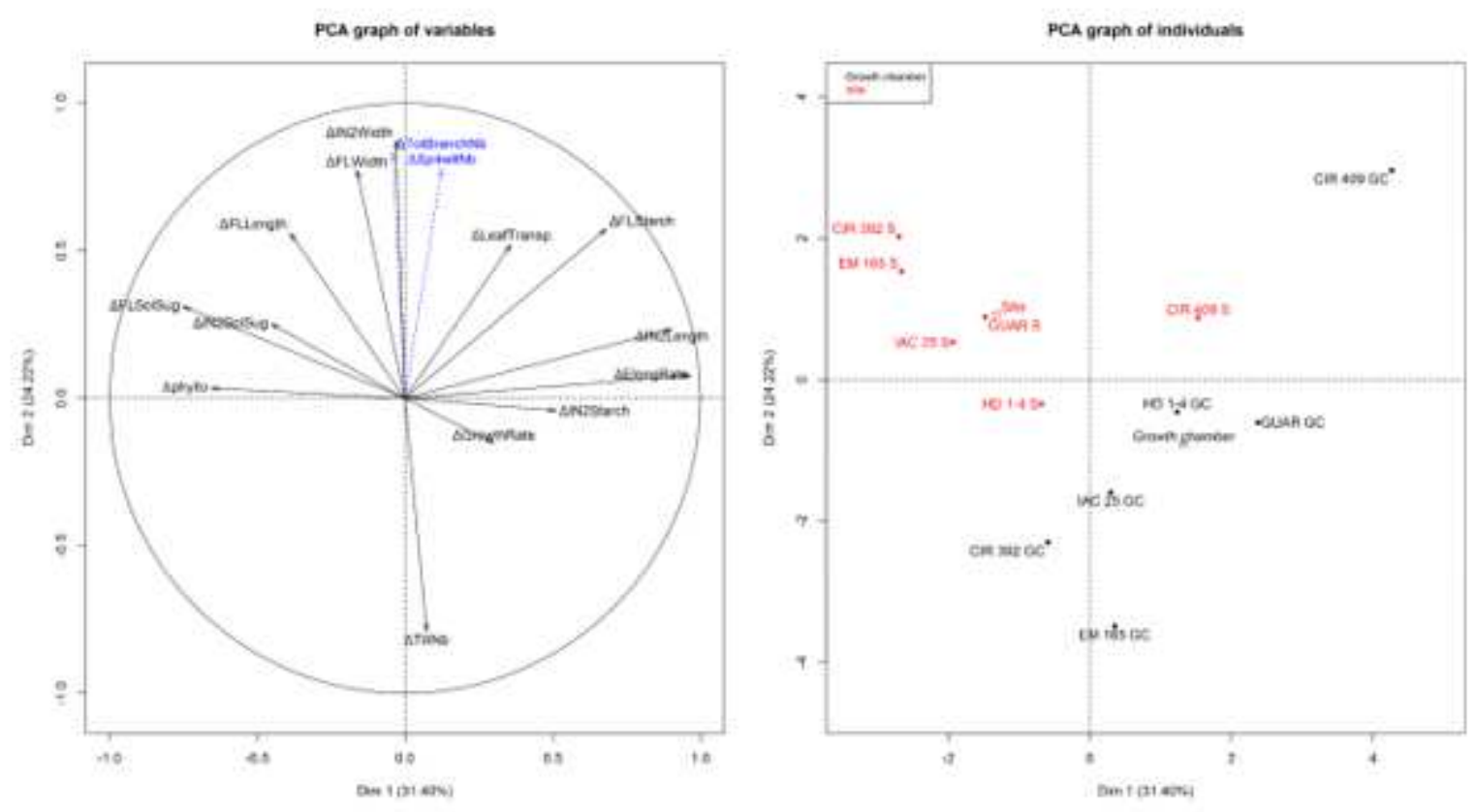

Figure 6

Principal Component Analysis representation on the two first components of the response index. 


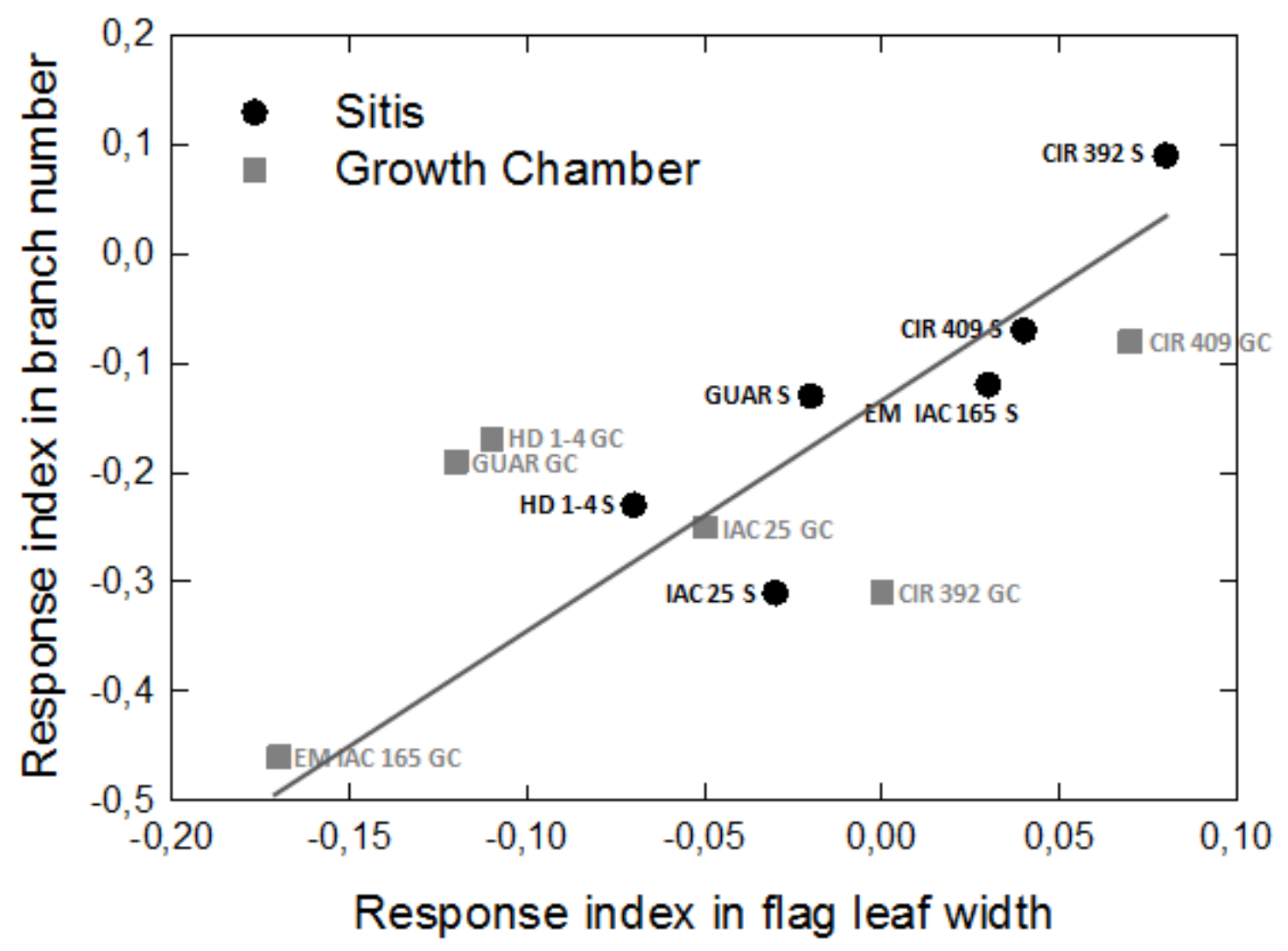

Figure 7

Relative variation of branch number and flag leaf width under water deficit. 